\title{
journal
}

\section{A Comprehensive Study on Compositional and Structural changes in 4555 Bioglass products exposed to Simulated Body Fluid}

\begin{tabular}{|r|l|}
\hline Journal: & Journal of the American Ceramic Society \\
\hline Manuscript ID & JACERS-39916.R1 \\
\hline Manuscript Type: & Article \\
\hline Date Submitted by the Author: & n/a \\
\hline Complete List of Authors: & $\begin{array}{l}\text { Montinaro, Selena; University of Cagliari, Dipartimento di Ingegneria } \\
\text { Meccanica, Chimica e dei Materiali } \\
\text { Desogus, Luca; Universita degli Studi di Cagliari, Dipartimento di } \\
\text { Ingegneria Meccanica, Chimica e dei Materiali } \\
\text { Orru, Roberto; University of Cagliari, Dipartimento di Ingegneria } \\
\text { Meccanica, Chimica e dei Materiali } \\
\text { Garroni, Sebastiano; Universidad de Burgos Facultad de Ciencias, } \\
\text { International Research Centre in Critical Raw Materials-ICCRAM } \\
\text { Delogu, Francesco; University of Cagliari, Dipartimento di Ingegneria } \\
\text { Meccanica, Chimica e dei Materiali } \\
\text { Ricci, Pier Carlo; Universita degli Studi di Cagliari, Dipartimento di Fisica } \\
\text { Cao, Giacomo; University of Cagliari, Dipartimento di Ingegneria } \\
\text { Meccanica, Chimica e dei Materiali }\end{array}$ \\
\hline Keywords: & \begin{tabular}{l} 
spark plasma sintering, bioceramics, glass, biocompatibility \\
\hline
\end{tabular} \\
\hline
\end{tabular}




\title{
A Comprehensive Study on Compositional and Structural changes in 4555 Bioglass products exposed to Simulated Body Fluid
}

\begin{abstract}
S. Montinaro ${ }^{1}$, L. Desogus ${ }^{1}$, R. Orrù ${ }^{1, *}$, S. Garroni ${ }^{2,3}$, F. Delogu ${ }^{1}$, P. C. Ricci ${ }^{4}$, G. Cao $^{1}$
${ }^{1}$ Dipartimento di Ingegneria Meccanica, Chimica e dei Materiali, Unità di Ricerca del Consorzio Interuniversitario Nazionale per la Scienza e Tecnologia dei Materiali (INSTM) Università degli Studi di Cagliari, via Marengo 2, 09123 Cagliari, Italy

${ }^{2}$ International Research Centre in Critical Raw Materials-ICCRAM, University of Burgos, Plaza Misael Banuelos s/n, 09001 Burgos, Spain

${ }^{3}$ Advanced Materials, Nuclear Technology and Applied Bio/Nanotechnology. Consolidated Research Unit UIC-154. Castilla y Leon. Spain.University of Burgos. Hospital del Rey s/n, 09001 Burgos, Spain.

${ }^{4}$ Dipartimento di Fisica, Università degli Studi di Cagliari, S.P. Monserrato-Sestu km 0.7, 09042 Monserrato (CA), Italy
\end{abstract}

* Author to whom correspondence should be addressed:

R. Orrù (E-mail: roberto.orru@dimcm.unica.it; Ph.: +39-070-6755076; Fax: +39-0706755057), Università degli Studi di Cagliari, via Marengo 2, 09123 Cagliari, Italy

\section{Submitted Revised Marked version}

March July 2017 


\begin{abstract}
The interaction of fully dense 45S5-bioglass derived samples produced by Spark Plasma Sintering (SPS) with Simulated Body Fluid (SBF) solution was investigated in detail taking advantage of the Rietveld refinement method to quantitatively evidence the corresponding microstructural and compositional changes. It is observed that, when the original amorphous nature is mostly $(75 \mathrm{wt} . \%)$ preserved in the material during sintering (550 ${ }^{\circ} \mathrm{C}, 2 \mathrm{~min}$ ), the resulting specimens dissolve faster and determine relatively higher $\mathrm{pH}$ increase and ions release in the SBF solution. Correspondingly, a relatively lower amount of hydroxycarbonate apatite (HCA) is formed on their surface. In contrast, a more extensive apatite layer with trabecular structure is generated within 3 days storage on the surface of fully crystallized samples obtained at $600{ }^{\circ} \mathrm{C}$ by SPS, which only consists of Na-Ca silicate grains $(20 \mathrm{~nm})$. Moreover, as the sintering temperature and dwell time were increased to 700 ${ }^{\circ} \mathrm{C}$ and $20 \mathrm{~min}$, respectively, a rhenanite-like phase was also formed (about $15 \mathrm{wt} . \%$ ), other than crystallites growth to $90 \mathrm{~nm}$. Interestingly, the presence of rhenanite provides a beneficial contribution for the production of the HCA layer, which was found the largest highest for this system when considering storage periods of 7 and 14 days, respectively.
\end{abstract}

Keywords: Spark Plasma Sintering; Bioactive glasses, In-vitro-test; Rietveld method 


\section{Introduction}

After the first bioactive glass was discovered in late 60s by Larry Hench and its ability to bond with bones and promote new bone generation well-recognized in the subsequent years, this class of materials has been broadly used in the biomedical field $-[1-3\} \cdot{ }^{1-3}$ In this context, depending on the specific application, the conventional 45S5 Bioglass ${ }^{\circledR}$ originally developed by Hench, composed of $45 \% \mathrm{SiO}_{2}-24.5 \% \mathrm{Na}_{2} \mathrm{O}-24.5 \% \mathrm{CaO}-6 \% \mathrm{P}_{2} \mathrm{O}_{5}$ (wt. \%), as well as other glass formulations proposed more recently, have been utilized as particulates, coatings or massive products, by orthopaedic surgeons and dentists $-[1-3\} \cdot{ }^{1-3}$ Despite the recent progress reached for these materials, an extensive and intense research is still ongoing to further improve their mechanical and biological properties, so that their potential application could be extended $\{2-3\} .^{2-3}$ In this regard, it is well known that several factors such as glass composition, porosity, surface/volume ratio, surface roughness, crystallinity degree, etc., affect the mechanical and biological behavior of this materials family. In particular, as far as the mechanical characteristics are concerned, the occurrence of crystallization in glass-ceramic products is generally found beneficial with respect to the completely amorphous counterpart. On the other hand, controversial results were reported in the literature regarding the effect of the crystallization from the parent glass on the material bioactivity. The latter characteristics is generally associated with the capability of the glass to form a hydroxycarbonate apatite (HCA) layer when in contact with biological fluids. Although the formation mechanism of HCA is rather well documented $[3\}^{3}$, the investigations conducted so far on the consequences produced by an enhancement of crystallization from the glass phase, do not result thoroughly clarified and appear to be even conflicting- $4-7\} .^{4-7}$ For instance, the formation of apatite was significantly delayed when highly crystallized bioglass specimens were used instead of samples containing a large fraction of the glassy phase $[4] .{ }^{4}$ On the same line, the time needed for the apatite formation during in-vitro test in Simulated Body Fluid (SBF) solution monotonically increased as the volume fraction of 
crystals in $45 \mathrm{~S} 5$ glass-ceramics was augmented up to $60 \%-[5] .{ }^{5}$ In addition, no further noticeable changes were observed to take place as the crystallization proceeded until its completion. Filho et al. ${ }^{5}$ (1996)-stressed the positive role played by the residual amorphous phase in the control of the ion exchange rate at the substrate-SBF interface $\left[5+{ }^{5}\right.$

In contrast to previous findings, the occurrence of crystallization phenomena in 45S5 Bioglass ${ }^{\circledR}$ was recently reported to improve the biological response of samples soaked in acellular SBF- 46$\}.{ }^{6}$ More specifically, calcium silicate and calcium carbonate, rather than HCA, were the only phases detected on the surface of 45S5 amorphous bioglass after storage in SBF up to 14 days. On the other hand, the formation of an apatite layer was clearly evidenced in crystallized samples obtained after heat-treatment at $1000{ }^{\circ} \mathrm{C}$ of the original (amorphous) material. Analogously, the presence of fine crystals in 45S5 Bioglass ${ }^{\circledR}$ samples, obtained by Spark Plasma Sintering (SPS) at $600{ }^{\circ} \mathrm{C}$, was found to promote the formation of HCA during in-vitro tests in SBF, compared to fully amorphous specimens produced with the same technique at $550{ }^{\circ} \mathrm{C}+77 .^{7}$

Other than controversial, the previously cited studies did not provide quantitative information on the amount of HCA formed during the in-vitro tests. This holds also generally true when considering the structural characteristics of the starting samples, e.g. crystallite sizes, crystallization degree, etc., before and in the course of biological experiments.

The scope of the present investigation is then to provide a useful contribution along this direction. To this aim, commercial 45S5 Bioglass ${ }^{\circledR}$ are first spark plasma sintered to produce three series of fully dense samples with different crystallization degree, crystallites size, and composition. The adopted SPS conditions are chosen on the basis of the results obtained in a recent study where the sintering behavior of the same kind of bioglass powders was investigated -88$\}.{ }^{8}$ The resulting $45 \mathrm{~S} 5$-based products are then stored for different time intervals (0-14 days) in SBF. The biological response provided by the three groups of materials is subsequently examined by properly monitoring their weight, compositional and 
morphological changes during the test. It should be noted that, to the best of our knowledge, the quantitative evaluation of the amount and crystallites size of apatite and other phases formed during the in-vitro test, or originally present in the substrate, is performed for the first time in the literature. In addition, all the modifications taking place on the surface of the different bioglass substrates will be associated with the corresponding variations in $\mathrm{pH}$ and ions concentration of the SBF solution to which specimens were exposed.

\section{Experimental Materials and Methods}

\subsection{Preparation of Bioglass disks}

Bioglass ${ }^{\circledR}$ 45S5 Glass Spheres (Cod. GL0160P, Mo-Sci Corp., USA) were consolidated under vacuum conditions (20 Pa) by Spark Plasma Sintering (SPS 515S model, Fuji Electronic Industrial Co., Ltd., Kanagawa, Japan) to produce dense cylindrical specimens with approximately $14.7 \mathrm{~mm}$ diameter and $3 \mathrm{~mm}$ thickness. The composition of initial powders, as provided by the vendor, was $24.4 \% \mathrm{Na}_{2} \mathrm{O}, 26.9 \% \mathrm{CaO}, 46.1 \% \mathrm{SiO}_{2}$ and $2.6 \mathrm{P}_{2} \mathrm{O}_{5}(\mathrm{~mol} . \%)$. Laser light scattering analysis (CILAS 1180, France) indicated that particles size was less than $15 \mu \mathrm{m}$ with an average value of about $4.5 \mu \mathrm{m}$. Further details relative to powders characteristics and SPS experiments are reported elsewhere- $[8\} .{ }^{8}$ Briefly, SPS experiments were carried out under temperature controlled mode using a K-type thermocouple (Omega Engineering Inc., USA) inserted inside a small hole drilled at the centre of the external surface of the graphite die. Fully dense samples with different crystallization degree and crystallite sizes were obtained by properly setting the dwell temperature $\left(T_{D}\right)$, holding time $\left(t_{D}\right)$ and mechanical pressure $(P)$ in the ranges $550-700{ }^{\circ} \mathrm{C}, 2$ $20 \mathrm{~min}$ and 16-70 $\mathrm{MPa}$, respectively. Specifically, the three groups of 45S5-based glass specimens prepared for in-vitro tests are reported in Table $\mathbf{1}$ along with the values of the corresponding sintering parameters. 
Before using bioglass-derived products for in-vitro experiments, they were first lapped using coarse abrasive paper and then finely polished. The resulting final samples thickness was about $2.6 \mathrm{~mm}$.

The residual surface roughness in the polished samples was measured using a Form Talysurf Intra 50 profilometer (Taylor-Hobson ltd., Leicester, UK). The obtained topological data were then analysed with the Ultra Software (Taylor-Hobson, Leicester, UK). The evaluation of roughness parameters was carried on 4 different profiles for each sample. In particular, the roughness parameter $R a$, defined as the arithmetic average of the deviation of peak heights and valleys of the roughness profile from the mean line, was determined.

\subsection{SBF experiments}

To evaluate their bioactivity, the spark plasma sintered bioglass samples were subjected to in-vitro tests following the Kokubo protocol- $\left[9+{ }^{9}\right.$ Accordingly, $1000 \mathrm{~mL}$ of acellular SBF was prepared by adding $8.035 \mathrm{~g}$ of $\mathrm{NaCl}, 0.355 \mathrm{~g}$ of $\mathrm{NaHCO}_{3}, 0.225 \mathrm{~g}$ of $\mathrm{KCl}$, $0.231 \mathrm{~g}$ of $\mathrm{K}_{2} \mathrm{HPO}_{4} \cdot 3 \mathrm{H}_{2} \mathrm{O}, 0.311 \mathrm{~g}$ of $\mathrm{MgCl}_{2} \cdot 6 \mathrm{H}_{2} \mathrm{O}, 39 \mathrm{~mL}$ of $1 \mathrm{M} \mathrm{HCl}, 0.292 \mathrm{~g}$ of $\mathrm{CaCl}_{2}$, $0.072 \mathrm{~g}$ of $\mathrm{Na}_{2} \mathrm{SO}_{4}, 6.118 \mathrm{~g}$ of Tris hydroxymethylaminomethane and $0-5 \mathrm{~mL}$ of $1 \mathrm{M} \mathrm{HCl}$ to distilled water. The solution was then buffered at $\mathrm{pH}=7.4$ using $1 \mathrm{M} \mathrm{HCl}$.

Each specimen was stored in about $46 \mathrm{~mL}$ of solution to obtain a sample surface area to the SBF volume constant ratio equal to $0.1 \mathrm{~cm}^{-1}$.

During the test, each specimen was stored in $45.93 \mathrm{~mL}$ of solution $\left(\mathrm{V}_{\mathrm{s}}\right)$, that was determined according to the Kokubo procedure ${ }^{9}$, i.e.:

$$
\mathrm{V}_{\mathrm{s}}(\mathrm{mL})=\mathrm{S}_{\mathrm{a}}\left(\mathrm{mm}^{2}\right) / 10
$$

where $S_{a}$ is the apparent surface area of the sample, i.e. $459.3 \mathrm{~mm}^{2}$ in the present study. The test was conducted at $37^{\circ} \mathrm{C}$ for different time periods, namely $6 \mathrm{~h}, 1,3,7$ and 14 days. For the sake of reproducibility, each SBF experiment was repeated at least three times. 


\subsection{Characterization}

After being soaked in the SBF solution, bioactive glass disks were immediately rinsed with distilled water and dried. Gravimetric measurements (Analytical balance, KERN mod. ABS 120-4, Balingen, Germany) were carried out at the end of each immersion step to determine samples weight changes during the test.

The crystalline phases initially present in the sintered samples and those ones subsequently formed after their immersion in the SBF solution were identified using a X-ray diffractometer (Philips PW 1830, Netherlands) equipped with a Ni filtered $\mathrm{Cu} \mathrm{K}_{\alpha}$ radiation $(\lambda=1.5405 \AA)$. A Rietveld analytical procedure was utilized to estimate the relative amount of the diverse phases originally present or formed during the test on the material surface as well as the related average crystallites size $[\mathbf{1 0}-\mathbf{1 2}] \cdot{ }^{10-12}$

The microstructure and compositional modifications taking place on the specimens surface were examined by high resolution scanning electron microscopy (HRSEM) (mod. S4000, Hitachi, Tokyo, Japan) equipped with a UltraDry EDS Detector (Thermo Fisher Scientific, Waltham, MA, USA).

Raman scattering measurements were carried out in backscattering geometry using a $632.8 \mathrm{~nm}$ line by He-Ne Laser. Measurements were performed at room temperature with a triple spectrometer Jobin-Yvon Dilor integrated system with a spectral resolution of about 1 $\mathrm{cm}^{-1}$. Spectra were recorded in the Stokes region by a 1200 groove/mm grating monochromator and a LN cooled charge coupled device (CCD) detector system.

To better evidence the impact produced at relatively longer time intervals by the interaction of the three bioglass systems with the surrounding solution, the latter one was not renewed during the entire period of soaking. Thus, $\mathrm{pH}$ and the concentration of some important species present in the solution $(\mathrm{Ca}, \mathrm{P}, \mathrm{Si}, \mathrm{Na})$ were monitored at the prescribed immersion time ends. The latter analysis was carried out by means of Inductively Coupled 
Plasma Optical Emission Spectroscopy (ICP-OES CCD Simultaneous, Vista - MPX Varian, Mulgrave, Australia).

\section{Results and discussion}

\subsection{Fabrication of bioglass samples}

The less severe SPS conditions identified in a recent study to achieve the full densification of the $45 \mathrm{~S} 5$ bioglass powders used in present work were $T_{D}=550{ }^{\circ} \mathrm{C}, t_{D}=2$ min, and $P=70 \mathrm{MPa}-[8\} .{ }^{8}$ The resulting sintered material mainly maintained its original glassy nature although the formation of a Na-Ca-silicate crystalline phase was also evidenced by the XRD analysis. This glass-ceramic biocomposite, indicated as 45S5_S1 in Table 1, represents the base systems tackled in this work for SBF tests. In addition, to highlight the possible effects of devitrification from the parent glass on the apatite formation during invitro experiments, the SPS temperature and processing time were increased to generate the two additional sets of bioceramics listed in Table 1 as 45S5_S2 and 45S5_S3. To produce the latter group of products, it should be noted that the applied pressure was lowered from 70 to $16 \mathrm{MPa}$ to avoid sample breakage due to the excessive thermo-mechanical stresses established during the sintering process.

\subsection{SBF experiments}

\subsubsection{Samples surface: XRD analysis}

The compositional and microstructural modifications occurring on the surface of the bioglass disks during in-vitro tests are first examined by XRD analysis. The Rietveld method was used to evaluate the relative content of the different phases present and the corresponding crystallites size. The experimental patterns (red rhombohedral) and the corresponding best-fit (dark line) related relative to the 45S5_S1 samples are reported in Figure 1. In addition, the 
obtained average crystallites size, microstrain and relative phases amount are summarized in

\section{Table 2.}

The first pattern, named "original powders", corresponds to an amorphous glass, heretoafter indicated as "amorphous 45S5" in Table 2, and which is computed using a pseudo-crystalline structure factor $\left(\mathrm{Ca}_{1.5} \mathrm{Na}_{2.64} \mathrm{Si}_{9} \mathrm{O}_{3}\right.$, card n. 01-078-1650 of the ICDD database, crystallite size: $20 \AA$, microstrain: 0.03 ) according to the LeBail approach $\left[13-15+{ }^{13-15}\right.$

The pattern indicated in Figure $\mathbf{1}$ as $\mathrm{t}=0 \mathrm{~d}$, corresponding to the dense product obtained by SPS under the conditions reported in Table 1 for 45S5_S1, shows the presence of an amorphous phase ( 75 wt.\%) together with Bragg reflections ascribable to $\mathrm{Ca}_{1.5} \mathrm{Na}_{2.64} \mathrm{Si}_{9} \mathrm{O}_{3}(25$ wt.\%). The deconvolution profiles of the pattern corresponding to $t=0 \mathrm{~d}$ can be better visualized in Figure 2. Therefore, It is apparent that a partial crystallization of the amorphous matrix occurs during the heat treatment process, although nanostructured domains (90 $\AA$ ) of $\mathrm{Ca}_{1.5} \mathrm{Na}_{2.64} \mathrm{O}_{9} \mathrm{Si}_{3}$, indicated as " nanocrystalline 45S5", are preserved after SPS.

The XRD analysis of the 45S5_S1 sample after $6 \mathrm{~h}$ in contact with the SBF solution evidenced some changes in the composition and surface microstructure with respect to the original ones. In particular, the peaks relative to the crystalline phase initially present in the sintered disk disappeared from the pattern. Moreover, after 1 day into SBF solution (pattern $\mathrm{t}$ $=1 \mathrm{~d}$ ), the system undergoes a further amorphization, as evidenced by the background increasing in the angular $2 \theta$ range $20-30^{\circ}$. On the other hand, reflections ascribable to nano hydroxyapatite (card n. 00-024-0033 of the ICDD database) are clearly distinguishable in the pattern referred as $\mathrm{t}=3 \mathrm{~d}$. Correspondingly, as reported in Table 2, nanodomains of around $15 \mathrm{~nm}$ are estimated for the apatite phase.

After 7 days, the amount of hydroxyapatite still increased up to 9 wt.\%. It is important to highlight that the sample presents shows a moderate texture with a preferred orientation situated on corresponding to the reflection $002\left(25.84^{\circ}\right)$ : the hydroxyapatite formed onto amorphous glass nucleates or grows growths with (002) oriented. This aspect is better 
emphasized in the sample stored for 14 days, where the peak (002) presents a unexpected intensity. Finally, the amount of nano apatite increases up to $15 \mathrm{wt} \%$ with respect to amorphous matrix.

The experimental patterns and the best-fit profiles of the 45S5_S2 samples, are reported in Figure 3, while the corresponding compositional and structural data are summarized in Table 3. As indicated in Table 1, relatively higher temperature, with respect to the 45S5_S1 case, were adopted to produce this class of samples. Such more severe annealing conditions are responsible for the drastic changes produced in the microstructure of the 45S5 glass, as evinced in the pattern reported in Figure 3 (pattern $t=0$ d). No amorphous phases can be detected in this pattern, supporting the almost complete crystallization event occurred to the glass during the SPS process for $2 \mathrm{~min}$ at the temperature of $600{ }^{\circ} \mathrm{C}$. However, as shown in Table 3, Rietveld analysis on the XRD pattern reveals that the crystallites size do not overcome $200 \AA \AA$. As for the previous system, the Rietveld procedure confirmed that the composition of this phase is $\mathrm{Ca}_{1.5} \mathrm{Na}_{2.64} \mathrm{O}_{9} \mathrm{Si}_{3}$.

In accordance with the behavior displayed by the $25 \mathrm{wt} \%$ crystallized system, the surface of 45S5_S2 samples also undergoes to a progressive amorphization when in contact with the SBF solution up to 1 day. Nonetheless, as the immersion time was prolonged to 3 days, the XRD analysis provided an unequivocal indication of the apatite formation. Specifically, under such condition, three main phases were detected in the sample, i.e. amorphous glass (65 wt.\%), nanocrystalline 45S5 (20 wt.\%) and nanohydroxyapatite (15 wt.\%). The amount of apatite was found to increase up to $21 \mathrm{wt} \%$ in samples stored for 7 days, and a further raise of the apatite phase content (25 wt.\%) was recorded in specimens immersed for 14 days into SBF solution. Another aspect evidenced by the Rietveld analysis (cf. Table 3) is that crystallites size of nanocrystalline 45S5 decreases from 20 to $13 \mathrm{~nm}$ during the course of the test. 
As reported in Table 1, the third group of samples (45S5_S3) was produced by SPS by increasing both the dwell temperature and holding time to $700{ }^{\circ} \mathrm{C}$ and $20 \mathrm{~min}$, respectively. Correspondingly, the amorphous phase crystallizes with a trigonal habitat and space group R-3m:H. In particular, this system presents shows crystallites size for the $\mathrm{Ca}_{1.5} \mathrm{Na}_{2.64} \mathrm{O}_{9} \mathrm{Si}_{3}$ phase of $900 \AA$, larger with respect to those ones present in the 45S5_S2 material. Moreover, a series of new peaks ascribable to an additional phase with rhenanitetype structure were also detected (Figure 4, $t=0 \mathrm{~d}$ ). In this work, these peaks are attributed to rhenanite $\left(\mathrm{NaCaPO}_{4}\right.$, card n. 29-1193 of the ICDD database), albeit it should be noted that they might also be associated with silicorhenanite $\left(\mathrm{Na}_{2} \mathrm{Ca}_{4}\left(\mathrm{PO}_{4}\right)_{2} \mathrm{SiO}_{4}\right)$, which is the formulation generally indicated in the literature for the crystalline phase formed when of 45S5 bioactive glass are heat treated at temperature above $800^{\circ} \mathrm{C}-416+{ }^{16}$ All the parameters obtained by the fit analysis are reported in Table 4.

Also for the case of the 45S5_S2 samples family, a partial amorphization of the material surface preceded the formation of the apatite phase during in-vitro test in SBF. Specifically, 10 wt. \% was the content of apatite revealed after 3 days. As the immersion time was prolonged to 7 days, a further progress in the amorphization of the material surface was observed in parallel to a higher amount (25 wt.\%) of apatite. Finally, the latter phase increased to $33 \mathrm{wt} . \%$ after 14 days in contact with the SBF solution.

Analogously to the 45S5_S2 system (cf. Table 3), Rietveld data relative to 45S5_S3 (cf. Table 4) also evidence that the initial crystallites size of nanocrystalline 45S5 (90 nm) is reduced during the test in SBF, mostly within three days from the beginning of samples storage, to approach values in the range $15-18 \mathrm{~nm}$.

For the sake of comparison, the time profiles showing the relative content of apatite, as estimated through the Rietveld procedure for the three classes of bioglass products, are reported in Figure 5. 


\subsubsection{Samples surface: SEM observation and EDX analysis}

To better assess the compositional and morphological changes taking place on the glass-ceramic composite samples during in-vitro tests, particularly for relatively short immersion time intervals (up to 3 days), the surfaces of the three groups of products were examined in detail by SEM and EDX. The obtained results are reported in Figures 6-8. The SEM micrographs shown in Figure $\mathbf{6 b}$ indicated that the specimens after $6 \mathrm{~h}$ immersion in SBF appeared fractured (45S5_S1 and 45S5_S2) or otherwise degraded (45S5_S3) on their surfaces. In any case, no evidence of the formation of new crystalline phases could be detected at this stage by SEM. However, the EDX analysis evidenced a significant change in the surface composition (cf. Figure 8-7). In particular, the relative content of $\mathrm{Na}$ and $\mathrm{Si}$ rapidly decreased from the original value, albeit it did not drop to zero after 6h storage. In parallel, the percentages of $\mathrm{Ca}$ and $\mathrm{P}$ markedly increased markedly, particularly when considering the 45S5_S2 system. It should be noted that, during such short time period, the $\mathrm{Ca} / \mathrm{P}$ atomic ratio strongly decreased from the original value of about 5.2 to approximately 1.5. As shown in Figure 6c, the SEM micrograph relative to 45S5_S1 samples stored in SBF for $24 \mathrm{~h}$ evidenced the presence of aggregated grains, approximately round shaped, on the bioglass surface. A different situation is encountered when the 45S5_S2 sample was tested under the same conditions. Indeed, in the latter case, the entire surface was almost wholly covered by a uniform and fine layer, with a trabecular bone-like structure. The latter phase is also present, although only barely detectable by SEM, on the surface of 45S5_S3 samples. The EDX analysis results reported in Figure 8-7 are quite consistent with the SEM observations. In particular, after 1 day storage, $\mathrm{Si}$ completely disappeared, $\mathrm{Na}$ further decreased while the relative contents of both $\mathrm{Ca}$ and $\mathrm{P}$ still increased. Correspondingly, a value for the $\mathrm{Ca} / \mathrm{P}$ atomic ratio in the range 1.5-1.6 resulted for all the three 45S5-based systems. SEM results relative to samples contacted for 3 days with SBF confirmed that a relatively large amount of the new phase was present on the surface of 45S5_S2 materials. 
The microstructure and composition of the latter one was examined in detail at higher magnifications, as shown in Figure 7-8. The reported micrograph indicates that this phase displays a trabecular-like morphology. Moreover, based on the EDX spectra, it basically consists of $\mathrm{Ca}, \mathrm{P}$ and $\mathrm{O}$ with traces of $\mathrm{Na}$ and $\mathrm{C}$. It should be noted that the small $\mathrm{C}$ signal appearing in the EDX spectra could be either due to the carbonation of the apatite layer but also to graphite used to guarantee the electric conduction of samples observed by SEM. Nonetheless, the issue related to the apatite carbonation will be clarified in next section taking advantage of Raman spectroscopy. On the other hand, the small $\mathrm{Na}$ signal is likely ascribable to the sample underneath the apatite layer. The EDX analysis revealed also that, as the soaking time was increased, the $\mathrm{Ca}$ and $\mathrm{P}$ at.\% reached a maximum value and then slightly decreased, whereas an opposite behavior was correspondingly observed for O. In parallel, the $\mathrm{Ca} / \mathrm{P}$ atomic ratio only slightly changed to finally reach an approximate value of about 1.6.

\subsubsection{Samples surface: Raman analysis}

The apatite phase formed on the surface of $45 \mathrm{~S} 5$ samples during the SBF test was further characterized by Raman spectroscopy. As an example, Figure 9 reports the Raman spectrum in the region between 900 and $1150 \mathrm{~cm}^{-1}$ relative to the 45S5_S2 sample soaked for a 3 days into the SBF solution. For comparison, that one relative to pure apatite is also shown.

Apatite reports several bands in this spectra region related to the phosphate Raman ones bands. In particular, the main peak at $965 \mathrm{~cm}^{-1}$ is assigned to the $v_{1}$ mode while the lower peaks in the region around $1050-1080 \mathrm{~cm}^{-1}$ are connected to the triply degeneration of the $v_{3}$ modes $[17\}{ }^{17}$

The peak related to $v_{1}$ mode of carbonate appears at about $1070 \mathrm{~cm}^{-1}$.In this regard, it was has been already observed in the literature ${ }^{18-19}$ [18-19]-that even small amounts of carbonate generate large variation in the Raman spectrum of apatite samples with a large broadening of the $v_{3}$ phosphate modes and the presence of the additional carbonate band. Moreover, if the 
amount of carbonate is above $3 \mathrm{wt} \%$, the contribution of the $v_{1}$ mode of carbonate mode overlaps the phosphate modes, thus avoiding a clear identification of the different degenerate features. In this view and according to Awonusi et al. ${ }^{18}-(2007)$ [18, the spectra of the carbonated apatite sample can be well fitted with three Gaussian: a first contribution at about $960 \mathrm{~cm}^{-1}$ related to the phosphate, a broad band at about $1050 \mathrm{~cm}^{-1}$, that takes into account the $v_{3}$ modes, and a broad signal at about $1070 \mathrm{~cm}^{-1}$ related to $\mathrm{CO}_{3}{ }^{2-} v_{1}$ mode (cf. Figure 9). Hence, a rough estimation of the carbonated content can be obtained from the ratio between the area of the $1070 \mathrm{~cm}^{-1}$ carbonate band and the $960 \mathrm{~cm}^{-1}$ phosphate contribution; in our analysis a ratio of 0.27 has been obtained which corresponds to about $8 \mathrm{wt} \%$ of carbonate content, according to Awonusi et al.-(2007) [18]. ${ }^{18}$ In conclusion, the Raman spectroscopy unequivocally confirmed that the formed phosphate phase consisted of carbonated hydroxyapatite (HCA).

\subsubsection{Sample weight loss}

Weight changes data of the three 45S5 groups of bioglass specimens during their immersion in the SBF solution are plotted in Figure 10. The obtained results indicate that mass losses, due to sample dissolution, always prevailed with respect to the corresponding gain, caused by the new phases formation on the materials surface. In addition, it is observed that dissolution phenomena are mainly confined to the first day of immersion, while they tends to become less important as the soaking time is progressively augmented. When the behavior of the three series of specimens is compared, it can be stated that weight loss takes place in the following order 45S5_S1 >> 45S5_S2 > 45S5_S3. In particular, the obtained data clearly indicated that, during the in-vitro test, the samples consisting for of the $75 \mathrm{wt} . \%$ of the glassy phase lose their mass almost twice with respect to the fully crystallized counterparts. 


\subsubsection{Changes in the SBF solution}

The time-evolution of $\mathrm{pH}$ in the SBF solution during the test is shown in Figure 11. For all the three bioglass systems, which exhibited a similar (qualitative) behavior, this parameter increases monotonically from its initial value. In addition, the major changes take place during the first three days of immersion in the SBF, while minor variations are observed during the progress of as the test proceeds. In any case, $\mathrm{pH}$ did not overcome the value of 8 . Nonetheless, in correspondence to $\theta$ f the prescribed storage time intervals, relatively higher pH were obtained according to the following order 45S5_S1 > 45S5_S2 > 45S5_S3.

The latter hierarchy holds also generally true when the differences between the concentration of some of the more relevant species present in the solution with respect to the initial values, are compared for the three bioglass groups, as reported in Figure 12. Firstly, it is seen that the main changes take place within 3 days from the beginning of the test. In addition, Ca and $\mathrm{Si}$ released were found relatively higher for 45S5_S1, whereas slightly superior $\mathrm{Na}$ concentration was revealed for the $\mathbf{4 5 S 5}$ _S3 system. The data relative to the P content plotted in Figure 12 display a monotonically decreasing behavior, for all groups of 45S5 samples, during the progress of the in-vitro test. Furthermore, a relatively higher depletion rate of $\mathrm{P}$ from the solution, particularly up to 3 days immersion, was detected when considering the 45S5_S2 samples.

\section{Discussion}

As mentioned in the Introduction section, the response of bioactive materials during invitro tests depends not only by the nominal composition of the system, i.e. that one of classical Bioglass ${ }^{\circledR}$ for the present study, but also by various several other factors. In particular, the relative density of bulk materials, topological aspects (surface roughness), type and content of crystallized phases formed during powders processing, crystallization degree, 
crystallites size, etc., also affect the interaction between the material and the physiological solution. Therefore, the discussion of the results obtained during in-vitro experiments in this investigation has to be preceded by an accurate analysis of the samples characteristics prior the biological test.

Since the main scope of this work is to highlight the consequences arising from the use of differently crystallized bioactive glasses on the apatite formation, the other possibly affecting features, particularly material porosity and surface roughness, have been minimized. In this regard, it should be first noted that the three groups of 45S5-based specimens considered for biological tests are completely dense. This outcome was confirmed by SEM observation of the corresponding cross sections, whose results are not reported here for the sake of brevity. In addition, before their immersion in the SBF solution, all samples were finely polished, so that the resulting residual roughness was very low. To support the latter statement, it should be noted that the measured values of the Ra parameter for the 45S5_S1, 45S5_S2 and 45S5_S3 specimens were $0.046 \pm 0.012,0.045 \pm 0.006$, and $0.036 \pm 0.006 \mu \mathrm{m}$, respectively. Of course, the latter roughness property will be unavoidably modified during the seaffolds samples immersion in the SBF solution due to the occurrence of dissolution phenomena and the deposition of new phases on the material surface.

As described in the previous section, the microstructural characteristics of the three different classes of sintered disks are consistent with the corresponding SPS parameters adopted to consolidate the bioglass powders (cf. Table 1). Specifically, when the latter ones were processed under the milder temperature $\left(550{ }^{\circ} \mathrm{C}\right)$ and holding time $(2 \mathrm{~min})$ conditions required, with an applied pressure of $70 \mathrm{MPa}$, to achieve their complete densification, about $75 \mathrm{wt} \%$ of the 45S5_S1 material preserved its original amorphous nature. On the other hand, the remaining fraction underwent devitrification during the heat treatment, to generate $9 \mathrm{~nm}$ sized nanocrystallites, whose composition was ascertained by the fitting procedure as $\mathrm{Ca}_{1.5} \mathrm{Na}_{2.64} \mathrm{Si}_{9} \mathrm{O}_{3}$. In this regard, it should be noted that the use of the Rietveld approach 
allowed us to identify a more precise formulation for the crystalline phase formed from the glass with respect to that one $\left(\mathrm{Na}_{2} \mathrm{Ca}_{2} \mathrm{Si}_{3} \mathrm{O}_{9}\right)$ indicated in our previous study $-[8]^{8}$ and reported in prior investigations addressed to $45 \mathrm{~S} 5$ bioglass processing either by SPS -20$\}^{20}$ or using alternative heat treatment methods $[5-6,21-22] \cdot{ }^{5-6,21-22}$ Moreover, additional formulations, for instance $\mathrm{Na}_{2} \mathrm{CaSi}_{2} \mathrm{O}_{6}[7\}^{7}$ or $\mathrm{Na}_{2} \mathrm{CaSi}_{3} \mathrm{O}_{8}[23\}^{23}$, were also attributed to the crystallized phases formed in 45S5 bioactive glasses during SPS. The difficulty in identifying the precise composition for such sodium-calcium-silicate is ascribed to the fact that all these phases not only display similar XRD patterns but are also prone to generate solid-solid solutions $[24\} .{ }^{24}$ In addition, the specific crystalline phase formed from 45S5 bioglass could also depend on particle size of original powders as well as the conditions adopted during heat treatment 224. ${ }^{24}$ In any case, the $\mathrm{Ca}_{1.5} \mathrm{Na}_{2.64} \mathrm{O}_{9} \mathrm{Si}_{3}$ composition was used in this work as it allowed us to reproduce more satisfactorily, with respect to the alternative silicate phases mentioned above, the XRD patterns of the SPSed samples taken into account.

As shown in Figure 3 and summarized in Table $3(t=0 \mathrm{~d})$, the slight augment of $50{ }^{\circ} \mathrm{C}$ in the dwell temperature, while maintaining the other SPS parameters unchanged, was anyhow sufficient to determine the crystallization completion from the glass phase as well an increase of the $\mathrm{Ca}_{1.5} \mathrm{Na}_{2.64} \mathrm{Si}_{9} \mathrm{O}_{3}$ crystallites size to $20 \mathrm{~nm}$ (45S5_S2). Finally, as the $\mathrm{T}_{\mathrm{D}}$ and $\mathrm{t}_{\mathrm{D}}$ values were both raised to $700^{\circ} \mathrm{C}$ and $20 \mathrm{~min}$, respectively, to produce the 45S5_S3 series of specimens, grains growth proceeded up to $90 \mathrm{~nm}$ (Table 4). Furthermore, in addition to the silicate phase, about 15 wt. $\%$ of $\mathrm{NaCaPO}_{4}$ with $80 \mathrm{~nm}$ grains sized was also formed during SPS in the latter group of samples.

Before examining the results obtained in the present work relatively to the behavior displayed by these three groups of samples during in-vitro tests, some preliminary considerations are worth to be made. In particular, it should be mentioned that the physiological media used in various studies reported in the literature were periodically refreshed $-25-27\rceil .{ }^{25-27}$ Such choice was aimed to maintain the ions concentration more stable 
during the test more stable. Relatively higher $\mathrm{Ca}$ and $\mathrm{P}$ amounts are consequently made available in the SBF solution, so that more favorable conditions for the formation of the apatite layer on the bioglass surface can be established. Alternatively, according to the procedure followed by other authors $[6,28-29\},{ }^{6,28-29}$ the SBF solution was not renewed during the course of the biological test conducted in the present work. The reason for that is to better highlight the different outcomes correspondingly produced, which might not be so apparent, particularly as far as the changes in the solution are concerned, if the SBF is frequently replaced.

Results relative to SBF experiments will be then analyzed. The data plotted in Figure 10 testify the superior weight loss manifested by the 45S5_S1 category of samples. This outcome can be readily associated with the primary amorphous nature of such system, which makes it more reactive, with respect to the fully crystalline 45S5_S2 and 45S5_S3 ones, when in contact with the solution. In addition, although the latter two groups of specimens displayed similar dissolution behavior, the 45S5_S2 samples decreased their weight markedly during the first week storage in SBF, as compared to 45S5_S3 ones. It is likely that the relatively larger grains boundary area made available by the presence of finer grains in the first kind of material justifies its preferential dissolution with respect to the second, coarser, one. It is also possible that the presence of rhenanite might play a role in this regard.

The chemical changes observed in the SBF solution are quite in agreement with the corresponding dissolution behavior and could be interpreted on the basis of the mechanism proposed in the literature for the apatite formation in bioactive glasses $[3\}$. $^{3}$ Firstly, the rapid increase of $\mathrm{pH}$ and concentration cations manifested by all groups of samples (cf. Figures 11 and 12) is a logical consequence of initial phenomena taking place at the glass-SBF solution interface, which involve the ion exchange of $\mathrm{Ca}^{2+}$ and $\mathrm{Na}^{+}$(material $\rightarrow$ solution) with $\mathrm{H}^{+}$ (solution $\rightarrow$ glass surface) $[3\} .^{3}$ The more significant $\mathrm{pH}$ increase and Ca release taking place for the 45S5_S1 system, followed by the 45S5_S2 and, finally, 45S5_S3 series of samples, is 
consistent with the dissolution character they exhibited. Also Si concentration profiles followed the same behavior. The only exception is represented by the preferential Na release observed for the case of 45S5_S3 products (cf. Figure 12), particularly at relatively short immersion times. In this regard, it was previously made the hypothesis that the presence of $\mathrm{NaCaPO}_{4}$ previously postulated could explain the dissolution behavior displayed by the latter class of materials. Therefore, it is likely that it could also likely influence the selective ions release during the in-vitro test.

Besides, more important is the comparison of the three series of bioglass samples relatively to the apatite formation is even more important. Surprisingly, different situations are encountered depending upon the immersion time taken into account. In particular, the results shown in Figure 5 for systems immersed for three days in SBF evidenced that the amount of apatite varies in the following decreasing order: 45S5_S2 > 45S5_S3 > 45S5_S1. The latter outcome was confirmed by SEM observations (Figure 6d) coupled with EDX analysis (Figure 7). Due to the detection limit of the XRD analysis, no reliable data on the apatite formation could be provided by the Rietveld procedure for storage time periods equal or shorter than 1 day. Nonetheless, the generation of the new phase after 1 day immersion was assessed by SEM (Figure 6c). Moreover, the related results also confirmed that more favorable conditions for the formation of a homogeneous apatite layer are established when considering the 45S5_S2 samples. This statement is further supported by the correspondingly more drastic reduction of $\mathrm{P}$ concentration in SBF (Figure 12), in particular for soaking times equal or shorter than 1 day. Indeed, the faster formation of the HCA layer on the surface of 45S5_S2 materials, has to be necessarily accompanied by a quicker consumption of the $\mathrm{P}$ species in the SBF solution.

On the basis of the obtained results, it is therefore possible to state that, among the three groups of 45S5-based bioceramics considered in this work, the fully crystallized samples exclusively consisting of $\mathrm{Ca}_{1.5} \mathrm{Na}_{2.64} \mathrm{Si}_{9} \mathrm{O}_{3}$ grains with average size of about $20 \mathrm{~nm}$ display 
superior capability to more rapidly produce more rapidly larger amounts of apatite within three days storage.

However, a slightly diverse situation was encountered when the contact period of the materials with the SBF solution was extended. Indeed, the surface of 45S5_S3 samples immersed for 7 and 14 days was relatively richer in HCA with respect to the other systems. As previously highlighted previously, the presence of rhenanite in this class of bioglass products was found to affect their interaction with SBF. In this regard, the lower mass loss they generally displayed (cf. Figure 10), and the corresponding less significant $\mathrm{pH}$ increase (cf. Figure 11), are expected to play a positive role in establishing more favorable conditions for the HCA formation and its preservation on the bioceramic surface at relatively longer immersion times. Nonetheless, Figure 5 still confirmed a lower amount of apatite on the surface of the $75 \mathrm{wt} . \%$ amorphous samples with respect to the other two groups of specimens. Therefore, the generation of the HCA layer is always preferably promoted in fully crystallized samples with respect to the glass-ceramic 45S5_S1 group, where the amorphous fraction prevails. These findings are then in contrast with the results obtained by Li et al. (1992) $[4\}^{4}$ and Filho et al.(1996) $[5\}^{5}$, who emphasized the negative effects produced by the bioglass crystallization on the apatite formation. The different bioglass formulation and physiological solution $\left[\mathrm{f}^{4}\right.$ and/or annealing method/conditions adopted to induce crystallization from the parent glass $[5]^{5}$ are possibly responsible for the observed discrepancies with respect to the present study. On the other hand, our findings are seem to be more consistent with those ones reported in recent studies where conventional sintering $[6]^{6}$ or the SPS method $\mathrm{Ffl}^{7}$ were used to promote the devitrification of $45 \mathrm{~S} 5$ bioglass. In particular, Grasso et al. $(\mathbf{2 0 1 3})^{7}$ found that the formation of HCA during in-vitro tests in SBF was facilitated by the presence of fine $\mathrm{Na}_{2} \mathrm{CaSi}_{2} \mathrm{O}_{6}$ crystals in dense samples obtained by SPS at $600^{\circ} \mathrm{C}-[7] .^{7}$ However, the different sintering conditions and characterization methods adopted in the latter two studies were not sufficient to evidence, also from the quantitative 
point of view, the experimental findings described in the present work from a quantitative point of view.

Some considerations to possibly explain the peculiar behavior exhibited by 45S5_S2 and 45S5_S3 samples will be finally made taking advantage of the mechanism of interaction recently proposed by Boccaccini et al. $(\mathbf{2 0 0 7})^{22}$ for Bioglass ${ }^{\circledR}$ based glass-ceramics seaffolds in $\mathrm{SBF}-22\}$. First of all, it was postulated that during storage the crystalline grains breakdown through preferential dissolution at crystal structural defects. This fact is consistent with the progressive reduction of crystallites size evidenced in both systems by the Rietveld analysis. In addition, the fact that ion-exchange is expected to take place preferably at the grains boundaries likely explains the larger amount of apatite formed during the first 3 days immersion on the surface of $\mathbf{4 5 S 5}$ _S2 samples, which exhibit relatively smaller crystallites size with respect to $\mathbf{4 5 S 5}$ _S3 specimens. On the other hand, as shown in Tables 3-4, the progressive crystallites refinement makes their size in the two class of biomaterials roughly similar, i.e. 13 and $15-18 \mathrm{~nm}$, so that the latter effect tends to vanish as the immersion time was increased. Under such circumstances, the presence of rhenanite-type ceramic makes the only relevant difference between the two systems. Thus, it is likely that this phase is responsible for the improved HCA formation. In this regard, it should be noted that in-vivo experiment involving various calcium phosphates including rhenanite, evidenced the capability of the latter phase to be transformed completely into apatite- $\left[30+{ }^{30}\right.$ The progressively decrease of rhenanite content during the in-vitro test conducted in the present work (cf. Table 4) supported the latter statement.

\section{Concluding remarks}

The biological response of three series of bioceramics obtained by SPS from 45S5 Bioglass powders was examined in detail. As revealed by the Rietveld analysis of the related XRD patterns, about 25 wt. $\%$ of the material underwent devitrification under the milder SPS 
conditions $\left(550{ }^{\circ} \mathrm{C}, 2 \mathrm{~min}\right)$ adopted to achieve the full powder densification in the first group of samples. The resulting crystalline phase $\left(\mathrm{Ca}_{1.5} \mathrm{Na}_{2.64} \mathrm{Si}_{9} \mathrm{O}_{3}\right)$ exhibits approximately $9 \mathrm{~nm}$ sized grains. The second class of 45S5-derived materials was obtained by increasing the dwell temperature to $600^{\circ} \mathrm{C}$. Correspondingly, the crystallization process from the parent glass went to completion accompanied by grains growth to $20 \mathrm{~nm}$. Finally, the third category of bioglasses was produced under the most severe SPS conditions here investigated $\left(700{ }^{\circ} \mathrm{C}\right.$, $20 \mathrm{~min}$ ) which determined not only a further increase of crystallites size $(90 \mathrm{~nm})$, but also the formation of a new phase characterized by a rhenanite-like structure, ascribed to $\mathrm{NaCaPO}_{4}$, whose content was estimated of approximately $15 \mathrm{wt} . \%$.

The in-vitro tests results involving the interaction of these samples with acellular SBF are briefly summarized in what follows:

a) within the entire immersion time period investigated, HCA formation is mostly promoted in the two series of fully crystallized samples instead of the mainly amorphous system; in addition, the latter one displayed the higher weight loss, and determined the more significant increase in $\mathrm{pH}$ and ions released; in this regard, it is important to note that too high $\mathrm{pH}$ levels have to be avoided as they might provoke cells damage or even their death;

b) a larger content of apatite was detected during the first 3 days immersion on the surface of specimens exclusively consisting of $\mathrm{Ca}_{1.5} \mathrm{Na}_{2.64} \mathrm{Si}_{9} \mathrm{O}_{3}$ with crystallites size of $20 \mathrm{~nm}$; such biological response is probably ascribed to the large grains boundary area made available by the presence of such nanocrystallites, which determines an intensification of ion-exchange phenomena and, in turn, the formation of the HCA layer;

c) the initial presence of the rhenanite phase in the third group of bioglass scaffolds products contributes favorably to the formation of larger amounts of HCA at relatively longer storage periods. 


\section{Acknowledgements}

The financial support for this work from Regione Autonoma della Sardegna (Italy), L.R. n.7/2007, CUP n. F71J11001070002, is gratefully acknowledged. One of us (L.D.) has performed his activity in the framework of the International PhD in Innovation Sciences and Technologies at the University of Cagliari, Italy. The authors thank Francesco Loy e Gabriele Conti (University of Cagliari, Italy) for their technical support. 


\section{References}

[1] Hench L L 2006 The Story of Bioglass B J Mater Sci Mater Med 17 967-978

[2] Rahaman MN, Day D E, Sonny Bal B, Fu Q, Jung S B, Bonewald L F, Tomsia A P 2011 Bioactive glass in tissue engineering Acta Biomater. 7(6) 2355-2373

[3] Jones J R 2013 Review of bioactive glass: From Hench to hybrids Acta Biomater 9(1) $4457-4486$

[4] Li P, Yang Q, Zhang F, Kokubo T 1992 The effect of residual glassy phase in a bioactive glass-ceramic on the formation of its surface apatite layer in vitro J. Mater. Sei. Mater. Med. 3(6) $452-456$

[5] Filho O P, Latorre G P, Hench L L 1996 Effect of crystallization on apatite-layer formation of bionctive glass 45S5. J. Bimed. Mater. Res. 30(4) 509514

[6] Plewinski M, Schickle K, Lindner M, Kirsten A, Weber M, Fischer H 2013_The effect of crystallization of bionctive bioglass $45 \mathrm{~S} 5$ - on apatite formation and degradation Dental Mater. 29(12) 1256-1264

[7] Grasso S, Chinnam R K, Porwal H, Boccaccini A R, Reece M J 2013 Low temperature spark plasma sintering of 45S5 Bioglass (B) J. Non-Cryst. Solids 362(1) 25-29

[8] Desogus L, Cuceu A, Montinaro S, Orrù R, Cao G, Bellucei D, Sola A, Cannillo V 2015 Classical Bioglass $($ and innovative $\mathrm{CaO}$-rich bioglass powders processed by Spark Plasma Sintering: a comparative study J Eur. Ceram. Soc. $354277-4285$

[9] Kokubo T, Takadama H 2006 How useful is SBF in predicting in vivo bone bioactivity? Biomaterials 2729072915

[10] Lutterotti L, Scardi P 1990 Simultaneous Structure and Size-Strain Refinement by the Rietveld Method J. Appl. Cryst. $23246-252$

[11] Lutterotti L, Gialanella S 1998 X-ray diffraction characterization of heavily deformed metallic specimens Acta Mater 46(1) 101-110

Journal of the American Ceramic Society 
[12] Scardi P, Lutterotti L, Maistrelli P 1994 Experimental Determination of the Instrumental Broadening in the Bragg-Brentano Geometry Powder Diffr. 9(3) 180-186

[13] Le Bail A 1995 Modelling the silica glass structure by Rietveld method J. Non-Cryst. Solids 183 39-42

[14] Lutterotti L, Ceccato R, Dal Maschio R, Pagani E 1998 Quantitative analysis of silicate glass in ceramic materials by the Rietveld method Mater Sci Forum 278-281 87-92

[15] Baser T A, Bariceo M, Enzo S, Vaughan G, Yavari A R 2008 Analysis of erystallization behavior of Fe48Cr15Mo14Y2C15B6 bulk metallic glass by synchrotron radiation J. Mater. Res. 23(8) $2166-2173$

[16] Lefebvre L, Chevalier J, Gremillard L, Zenati R, Thollet G, Bernache-Assolant D, Govin A 2007 Structural transformations of bionctive glass $45 \mathrm{S5}$ with thermal treatments Acta Mater. 5533053313

[17] Penel G, Leroy G, Rey C, Sombret B, Huvenne JP, Bres E 1997 Infrared and Raman microspectrometry study of fluor-fluor-hydroxy and hydroxy-apatite powders $J$. Mater Sei. Mater. Med. $8271-276$

[18] Awonusi A, Morris M D, Tecklenburg M M 2007 Carbonate assignment and ealibration in the Raman spectrum of apatite Calcif. Tissue Int. 814652

[19] Morris M D, Mandair G S 2011 Raman Assessment of Bone Quality Clin. Orthop. Relat. Res. 46921602169

[20] Chen Q Z, Xu J L, Yu L G, Fang X Y, Khor K A 2012 Spark plasma sintering of solgel derived 45S5 Bioglass $B$-ceramics: Mechanical properties and biocompatibility evaluation Mater Sei Eng C 32494502

[21] Clupper D C, Hench L L 2003 Crystallization kinetics of tape cast bioactive glass 45S5 J. Non-Cryst. Solids $\mathbf{3 1 8} 43-48$

Journal of the American Ceramic Society 
[22] Boccaccini A R, Chen Q, Lefebvre L, Gremillard L, Chevalier J 2007 Sintering, erystallisation and biodegradation behaviour of Bioglass-derived glass-ceramics Faraday Diseuss. 136 27-44.[24]

[23] Porwal H, Grasso S, Cordero-Arias L, Li C, Boccaccini A R, Reece M J 2014 Processing and bioactivity of 45S5 Bioglass $($-graphene nanoplatelets composites $J$. Mater. Sci. Mater. Med. 25(6) 1403-1413

[24] Bellucei D, Cannillo V, Sola A 2010 An Overview of the Effect of Thermal Processing en Bioactive Glasses Sei. Sinter. 42 307-320

[25] Bellueci D, Cannillo V, Sola A, Chiellini F, Gazzarri M, Migene C 2011 Macroporous Bioglass (B-derived seaffolds for bone tissue regeneration Ceram. Int. 3715751585

[26] Zheng K, Solodornyk A, Li W, Goudouri OM, Stähli C, Nazhat SN, Boceaceini A R 2015 Aging Time and Temperature Effects on the Structure and Bionctivity of Gel Derived45S5-Glass Ceramies J. Am. Ceram. Soc. 983038

[27] Boccardi E, Melli V, Catignoli G, Altomare L, Jahromi M T, Cerruti M, Lefebvre L P, De Nardo L 2016 Study of the mechanical stability and bioactivity of Bioglass $B$ based glass-ceramic scaffolds produced via powder metallurgy-inspired technology Biomed. Mater. () 11(1) 015005

[28] Essien E R; Adams L A, Shaibu R O, Olasupo I A, Oki A 2012 Economic route to sodium-containing silicate bioactive glass scaffold Open Journal of Regenerative Medicine 1(3) $33-40$

[29] Mačković M, Hoppe A, Detsch R, Mohn D, Stark W J, Spiecker E, Boceaccini A R 2012 Bioactive glass (type 45S5) nanoparticles: in vitro reactivity on nanoscale and biocompatibility J. Nanopart. Res. $14966-987$

[30] Driessens F C M, Ramselaar M M A, Schaeken H G, Stols A L H, Van Mullem P J, De Wijn J R 1992 Chemical reactions of calcium phosphate implants after implantation in vivo J. Mater. Sei. Mater. Med. 3(6) 413-417 
1. Hench LL. The Story of Bioglass ${ }^{\circledR}$. J Mater Sci Mater Med. 2006;17:967-978.

2. Rahaman MN, Day DE, Sonny Bal B, et al. Bioactive glass in tissue engineering. Acta Biomater. 2011;7(6): 2355-2373.

3. Jones JR. Review of bioactive glass: From Hench to hybrids. Acta Biomater. 2013;9(1):4457-4486.

4. Li P, Yang Q, Zhang F, Kokubo T. The effect of residual glassy phase in a bioactive glass-ceramic on the formation of its surface apatite layer in vitro. J. Mater. Sci. Mater. Med. 1992;3(6):452-456.

5. Filho OP, Latorre GP, Hench LL. Effect of crystallization on apatite-layer formation of bioactive glass 45S5. J. Biomed. Mater. Res. 1996;30(4):509-514.

6. Plewinski M, Schickle K, Lindner M, et al. The effect of crystallization of bioactive bioglass 45S5 on apatite formation and degradation. Dental Mater. 2013;29(12):12561264.

7. Grasso S, Chinnam RK, Porwal H, et al. Low temperature spark plasma sintering of 45S5 Bioglass ${ }^{\circledR}$. J. Non-Cryst. Solids. 2013;362(1):25-29.

8. Desogus L, Cuccu A, Montinaro S, et al. Classical Bioglass ${ }^{\circledR}$ and innovative CaO-rich bioglass powders processed by Spark Plasma Sintering: a comparative study. J Eur. Ceram. Soc. 2015;35:4277-4285.

9. Kokubo T, Takadama H. How useful is SBF in predicting in vivo bone bioactivity? Biomaterials. 2006;27:2907-2915.

10. Lutterotti L, Scardi P. Simultaneous Structure and Size-Strain Refinement by the Rietveld Method. J. Appl. Cryst. 1990;23:246-252.

11. Lutterotti L, Gialanella S. X-ray diffraction characterization of heavily deformed metallic specimens. Acta Mater. 1998;46(1):101-110. 
12. Scardi P, Lutterotti L, Maistrelli P. Experimental Determination of the Instrumental Broadening in the Bragg-Brentano Geometry. Powder Diffr. 1994;9(3):180-186.

13. Le Bail A. Modelling the silica glass structure by Rietveld method. J. Non-Cryst. Solids. 1995;183:39-42.

14. Lutterotti L, Ceccato R, Dal Maschio R, et al. Quantitative analysis of silicate glass in ceramic materials by the Rietveld method. Mater Sci Forum. 1998;278-281:87-92.

15. Baser TA, Baricco M, Enzo S, et al. Analysis of crystallization behavior of Fe48Cr15Mo14Y2C15B6 bulk metallic glass by synchrotron radiation. J. Mater. Res. 2008;23(8):2166-2173.

16. Lefebvre L, Chevalier J, Gremillard L, et al. Structural transformations of bioactive glass 45S5 with thermal treatments. Acta Mater. 2007;55:3305-3313.

17. Penel G, Leroy G, Rey C, et al. Infrared and Raman microspectrometry study of fluorfluor-hydroxy and hydroxy-apatite powders. J. Mater Sci. Mater. Med. 1997;8:271276.

18. Awonusi A, Morris MD, Tecklenburg MM. Carbonate assignment and calibration in the Raman spectrum of apatite. Calcif. Tissue Int. 2007;81:46-52.

19. Morris MD, Mandair GS. Raman Assessment of Bone Quality. Clin. Orthop. Relat. Res. 2011;469:2160-2169.

20. Chen QZ, Xu JL, Yu LG, et al. Spark plasma sintering of sol-gel derived 45S5 Bioglass ${ }^{\circledR}$-ceramics: Mechanical properties and biocompatibility evaluation. Mater Sci Eng C. 2012;32:494-502.

21. Clupper DC, Hench LL. Crystallization kinetics of tape cast bioactive glass 45S5. J. Non-Cryst. Solids. 2003;318:43-48.

22. Boccaccini AR, Chen Q, Lefebvre L, et al. Sintering, crystallisation and biodegradation behaviour of Bioglass-derived glass-ceramics. Faraday Discuss. 2007;136:27-44. 
23. Porwal H, Grasso S, Cordero-Arias L, et al. Processing and bioactivity of 45S5 Bioglass ${ }^{\circledR}$-graphene nanoplatelets composites. J. Mater. Sci. Mater. Med. 2014;25(6):1403-1413.

24. Bellucci D, Cannillo V, Sola A. An Overview of the Effect of Thermal Processing on Bioactive Glasses. Sci. Sinter. 2010;42:307-320.

25. Bellucci D, Cannillo V, Sola A, et al. Macroporous Bioglass ${ }^{\circledR}$-derived scaffolds for bone tissue regeneration. Ceram. Int. 2011;37:1575-1585.

26. Zheng K, Solodovnyk A, Li W, et al. Aging Time and Temperature Effects on the Structure and Bioactivity of Gel-Derived 45S5 Glass-Ceramics. J. Am. Ceram. Soc. $2015 ; 98: 30-38$.

27. Boccardi E, Melli V, Catignoli G, et al. Study of the mechanical stability and bioactivity of Bioglass ${ }^{\circledR}$ based glass-ceramic scaffolds produced via powder metallurgy-inspired technology. Biomed. Mater. 2016;11(1):015005.

28. Essien ER; Adams LA, Shaibu RO, et al. Economic route to sodium-containing silicate bioactive glass scaffold. Open Journal of Regenerative Medicine 2012;1(3):33-40.

29. Mačković M, Hoppe A, Detsch R, et al. Bioactive glass (type 45S5) nanoparticles: in vitro reactivity on nanoscale and biocompatibility. J. Nanopart. Res. 2012;14:966-987.

30. Driessens FCM, Ramselaar MMA, Schaeken HG, et al. Chemical reactions of calcium phosphate implants after implantation in vivo. J. Mater. Sci. Mater. Med. 1992;3(6):413-417. 
Table 1. Designation of 45S5 bioglass samples and related SPS conditions

\begin{tabular}{lccc}
\hline Sample ID & $\mathbf{T}_{\mathbf{D}}\left({ }^{\circ} \mathbf{C}\right)$ & $\mathbf{t}_{\mathbf{D}}(\mathbf{m i n})$ & $\mathbf{P}(\mathbf{M P a})$ \\
\hline 45S5_S1 & 550 & 2 & 70 \\
45S5_S2 & 600 & 2 & 70 \\
& & & \\
45S5_S3 & 700 & 20 & 16 \\
\hline
\end{tabular}

17 
1

2

3

4

5

6

7

8

9

10

11

12

13

14

15

16

17

18

19

20

21

22

23

24

25

26

27

28

29

30

31

32

33

34

35

36

37

38

39

40

41

42

43

44

45

46

47

48

49

50

51

52

53

54

55

56

57

58

59

60

Table 2. Phases and quantitative phase analysis results relatively to 45S5_S1 samples stored in the SBF for different time intervals.

\begin{tabular}{|c|c|c|c|c|}
\hline Sample & Phases & $\begin{array}{l}\text { Crystallite } \\
\text { sizes }\end{array}$ & Microstrain & wt. $\%$ \\
\hline $\begin{array}{l}\text { Original } \\
\text { powders }\end{array}$ & Amorphous 45S5 & & & 100 \\
\hline$t=0 d$ & $\begin{array}{c}\text { Amorphous } 45 \mathrm{~S} 5 / \text { nanocrystalline } \\
45 \mathrm{~S} 5\end{array}$ & $/ 90 \AA$ & $/ 1 * 10^{-3}$ & $75 / 25$ \\
\hline $\mathrm{t}=6 \mathrm{~h}$ & New amorphous phase & & & $>95$ \\
\hline$t=1 d$ & New amorphous phase & & & $>95$ \\
\hline$t=3 d$ & New amorphous phase / apatite & $/ 150 \AA$ & $/ 4 * 10^{-3}$ & $93 / 7$ \\
\hline$t=7 d$ & New amorphous phase / apatite & $/ 230 \AA$ & $/ 4 * 10^{-3}$ & $91 / 9$ \\
\hline $\mathrm{t}=14 \mathrm{~d}$ & New amorphous phase / apatite & $/ 190 \AA$ & $/ 3 * 10^{-3}$ & $85 / 15$ \\
\hline
\end{tabular}


Table 3. Phases and quantitative phase analysis results relatively to 45S5_S2 samples stored in the SBF for different time intervals.

\begin{tabular}{|c|c|c|c|c|}
\hline Sample & Phases & $\begin{array}{c}\text { Crystallite } \\
\text { sizes }\end{array}$ & Microstrain & wt. $\%$ \\
\hline $\begin{array}{l}\text { Original } \\
\text { powders }\end{array}$ & Amorphous 45S5 & & & 100 \\
\hline $\mathrm{t}=0 \mathrm{~d}$ & Nanocrystalline 45S5 & 200 & $/ 1 * 10^{-3}$ & 100 \\
\hline $\mathrm{t}=6 \mathrm{~h}$ & $\begin{array}{l}\text { New amorphous phase/ } \\
\text { nanocrystalline } 45 \mathrm{~S} 5\end{array}$ & $/ 200$ & $/ 1 * 10^{-3}$ & $10 / 90$ \\
\hline$t=1 d$ & $\begin{array}{c}\text { New amorphous phase/ } \\
\text { nanocrystalline 45S5 }\end{array}$ & $/ 180$ & $/ 1 * 10^{-3}$ & $30 / 70$ \\
\hline$t=3 d$ & $\begin{array}{c}\text { New amorphous phase/ } \\
\text { nanocrystalline 45S5/apatite }\end{array}$ & $/ 130 / 210$ & $/ 1 * 10^{-3} / 5 * 10^{-3}$ & $65 / 20 / 15$ \\
\hline$t=7 d$ & $\begin{array}{c}\text { New amorphous phase/ } \\
\text { nanocrystalline 45S5/apatite }\end{array}$ & $/ 130 / 170$ & $/ 1 * 10^{-3} / 5^{*} 10^{-3}$ & $64 / 15 / 21$ \\
\hline$t=14 d$ & $\begin{array}{c}\text { New amorphous phase/ } \\
\text { nanocrystalline 45S5/apatite }\end{array}$ & $/ 130 / 220$ & $/ 2 * 10^{-3} / 4 * 10^{-3}$ & $65 / 10 / 25$ \\
\hline
\end{tabular}

Journal of the American Ceramic Society 
1

2

3

4

5

6

7

8

9

10

Table 4. Phases and quantitative phase analysis results relatively to 45S5_S3 samples stored in the SBF for different time intervals.

\begin{tabular}{|c|c|c|c|c|}
\hline Sample & Phases & $\begin{array}{l}\text { Crystallite } \\
\text { sizes }\end{array}$ & Microstrain & wt. $\%$ \\
\hline $\begin{array}{l}\text { Original } \\
\text { powders }\end{array}$ & Amorphous 45S5 & & & 100 \\
\hline$t=0 d$ & $\begin{array}{l}\text { Nanocrystalline } \\
\text { 45S5/rhenanite }\end{array}$ & $900 / 800$ & $2 * 10^{-3} / 4 * 10^{-3}$ & $85 / 15$ \\
\hline$t=6 \mathrm{~h}$ & $\begin{array}{l}\text { New amorphous phase/ } \\
\text { nanocrystalline } 45 \mathrm{~S} 5 / \\
\text { rhenanite }\end{array}$ & $/ 900 / 700$ & $1 * 10^{-3} / 3 * 10^{-3}$ & $8 / 86 / 6$ \\
\hline$t=1 d$ & $\begin{array}{l}\text { New amorphous phase/ } \\
\text { nanocrystalline 45S5/ } \\
\text { rhenanite }\end{array}$ & $/ 600 / 650$ & $1 * 10^{-3} / 3^{*} 10^{-3}$ & $12 / 84 / 3$ \\
\hline$t=3 d$ & $\begin{array}{c}\text { New amorphous phase/ } \\
\text { nanocrystalline 45S5/apatite }\end{array}$ & $/ 150 / 260$ & $/ 1 * 10^{-3} / 5^{*} 10^{-3}$ & $60 / 30 / 10$ \\
\hline$t=7 d$ & $\begin{array}{c}\text { New amorphous phase/ } \\
\text { nanocrystalline 45S5/apatite }\end{array}$ & $/ 160 / 280$ & $/ 1 * 10^{-3} / 5 * 10^{-3}$ & $55 / 20 / 25$ \\
\hline$t=14 d$ & $\begin{array}{c}\text { New amorphous phase/ } \\
\text { nanocrystalline 45S5/apatite }\end{array}$ & $/ 180 / 131$ & $/ 1 * 10^{-3} / 1 * 10^{-3}$ & $52 / 15 / 33$ \\
\hline
\end{tabular}




\section{Captions figures}

Figure 1. XRD patterns and related Rietveld refinements of 45S5_S1 samples as a function of the immersion time in the SBF solution. Data relative to the original bioglass powders are also shown for the sake of comparison. Label $45 \mathrm{~S} 5$ refers to the $\mathrm{Ca}_{1.5} \mathrm{Na}_{2.64} \mathrm{Si}_{9} \mathrm{O}_{3}$ phase.

Figure 2. Deconvolution of the XRD pattern relative to the SPSed 45S5_S1 product before being immersed in the SBF solution.

Figure 3. XRD patterns and related Rietveld refinements of 45S5_S2 samples as a function of the immersion time in the SBF solution. Data relative to the original bioglass powders are also shown for the sake of comparison. Label 45S5 refers to the $\mathrm{Ca}_{1.5} \mathrm{Na}_{2.64} \mathrm{Si}_{9} \mathrm{O}_{3}$ phase.

Figure 4. XRD patterns and related Rietveld refinements of 45S5_S3 samples as a function of the immersion time in the SBF solution. Data relative to the original bioglass powders are also shown for the sake of comparison. Label $45 \mathrm{~S} 5$ refers to the $\mathrm{Ca}_{1.5} \mathrm{Na}_{2.64} \mathrm{Si}_{9} \mathrm{O}_{3}$ phase.

Figure 5. Temporal changes of apatite content on the surface of the three class of 45S5bioglass samples during in-vitro test, as revealed by the Rietveld analysis.

Figure 6. SEM micrographs (5000X) of the three groups of $45 \mathrm{~S} 5$ specimens at different immersion times in the SBF solution: (a) $0 \mathrm{~h}$, (b) $6 \mathrm{~h}$, (c) $1 \mathrm{~d}$, and (d) $3 \mathrm{~d}$.

Figure 7. Detailed micrograph, and related EDX analysis result, of the surface of $\mathbf{4 5 S 5}$ _S2 sample after immersion for 3 days in the SBF solution.

Figure 87. Compositional changes, as revealed by EDX analysis, taking place on the surface of the three groups of $45 \mathrm{~S} 5$ specimens during their immersion in the SBF solution.

Figure 8. Detailed micrograph, and related EDX spectra, of the surface of 45S5_S2 sample after immersion for 3 days in the SBF solution. The EDX analysis provided the following results: Ca: 34 at. \%, P: 21 at.\%, O: 44 at. \%, and Na: 1 at.\%. The contribution of the $\mathrm{C}$ signal was not considered, due to the presence of graphite used to guarantee the electric contact in samples examined by SEM.

Journal of the American Ceramic Society 
Figure 9. Raman spectrum of the 45S5_S2 sample immersed for 3 days in SBF. The Raman data of pure apatite is also shown for the sake of comparison.

Figure 10. Weight changes of the three groups of $45 \mathrm{SS}$ specimens as a function of immersion times in the SBF solution.

Figure 11. Temporal evolution in $\mathrm{pH}$ of the SBF solutions where the three groups of $45 \mathrm{~S} 5$ specimens were immersed.

Figure 12. ICP results Compositional changes of the SBF solutions where the three series of 45S5 samples were soaked up to 14 days. 


\title{
A Comprehensive Study on Compositional and Structural changes in $45 \mathrm{S5}$ Bioglass products exposed to Simulated Body Fluid
}

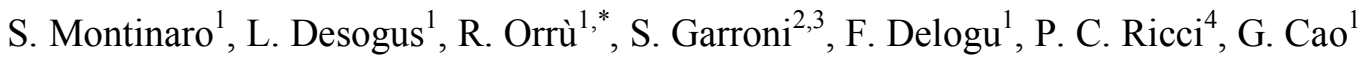

${ }^{1}$ Dipartimento di Ingegneria Meccanica, Chimica e dei Materiali, Unità di Ricerca del Consorzio Interuniversitario Nazionale per la Scienza e Tecnologia dei Materiali (INSTM) Università degli Studi di Cagliari, via Marengo 2, 09123 Cagliari, Italy

${ }^{2}$ International Research Centre in Critical Raw Materials-ICCRAM, University of Burgos, Plaza Misael Banuelos s/n, 09001 Burgos, Spain

${ }^{3}$ Advanced Materials, Nuclear Technology and Applied Bio/Nanotechnology. Consolidated Research Unit UIC-154. Castilla y Leon. Spain.University of Burgos. Hospital del Rey s/n, 09001 Burgos, Spain.

${ }^{4}$ Dipartimento di Fisica, Università degli Studi di Cagliari, S.P. Monserrato-Sestu km 0.7, 09042 Monserrato (CA), Italy
\end{abstract}

* Author to whom correspondence should be addressed:

R. Orrù (E-mail: roberto.orru@dimcm.unica.it; Ph.: +39-070-6755076; Fax: +39-0706755057), Università degli Studi di Cagliari, via Marengo 2, 09123 Cagliari, Italy

\section{Revised version}

July 2017 


\section{Abstract}

The interaction of fully dense 45S5-bioglass derived samples produced by Spark Plasma Sintering (SPS) with Simulated Body Fluid (SBF) solution was investigated in detail taking advantage of the Rietveld refinement method to quantitatively evidence the corresponding microstructural and compositional changes. It is observed that, when the original amorphous nature is mostly $(75 \mathrm{wt} . \%)$ preserved in the material during sintering (550 ${ }^{\circ} \mathrm{C}, 2 \mathrm{~min}$ ), the resulting specimens dissolve faster and determine relatively higher $\mathrm{pH}$ increase and ions release in the SBF solution. Correspondingly, a relatively lower amount of hydroxycarbonate apatite (HCA) is formed on their surface. In contrast, a more extensive apatite layer with trabecular structure is generated within 3 days storage on the surface of fully crystallized samples obtained at $600{ }^{\circ} \mathrm{C}$ by SPS, which only consists of Na-Ca silicate grains $(20 \mathrm{~nm})$. Moreover, as the sintering temperature and dwell time were increased to 700 ${ }^{\circ} \mathrm{C}$ and $20 \mathrm{~min}$, respectively, a rhenanite-like phase was also formed (about $15 \mathrm{wt} . \%$ ), other than crystallites growth to $90 \mathrm{~nm}$. Interestingly, the presence of rhenanite provides a beneficial contribution for the production of the HCA layer, which was found the largest for this system when considering storage periods of 7 and 14 days, respectively.

Keywords: Spark Plasma Sintering; Bioactive glasses, In-vitro-test; Rietveld method 


\section{Introduction}

After the first bioactive glass was discovered in late 60s by Larry Hench and its ability to bond with bones and promote new bone generation well-recognized in the subsequent years, this class of materials has been broadly used in the biomedical field. ${ }^{1-3}$ In this context, depending on the specific application, the conventional 45S5 Bioglass ${ }^{\circledR}$ originally developed by Hench, composed of $45 \% \mathrm{SiO}_{2}-24.5 \% \mathrm{Na}_{2} \mathrm{O}-24.5 \% \mathrm{CaO}-6 \% \mathrm{P}_{2} \mathrm{O}_{5}$ (wt. \%), as well as other glass formulations proposed more recently, have been utilized as particulates, coatings or massive products, by orthopaedic surgeons and dentists. ${ }^{1-3}$ Despite the recent progress reached for these materials, an extensive and intense research is still ongoing to further improve their mechanical and biological properties, so that their potential application could be extended. ${ }^{2-3}$ In this regard, it is well known that several factors such as glass composition, porosity, surface/volume ratio, surface roughness, crystallinity degree, etc., affect the mechanical and biological behavior of this materials family. In particular, as far as the mechanical characteristics are concerned, the occurrence of crystallization in glass-ceramic products is generally found beneficial with respect to the completely amorphous counterpart.

On the other hand, controversial results were reported in the literature regarding the effect of the crystallization from the parent glass on the material bioactivity. The latter characteristics is generally associated with the capability of the glass to form a hydroxycarbonate apatite (HCA) layer when in contact with biological fluids. Although the formation mechanism of HCA is rather well documented ${ }^{3}$, the investigations conducted so far on the consequences produced by an enhancement of crystallization from the glass phase, do not result thoroughly clarified and appear to be even conflicting. ${ }^{4-7}$ For instance, the formation of apatite was significantly delayed when highly crystallized bioglass specimens were used instead of samples containing a large fraction of the glassy phase. ${ }^{4}$ On the same line, the time needed for the apatite formation during in-vitro test in Simulated Body Fluid (SBF) solution monotonically increased as the volume fraction of crystals in $45 \mathrm{~S} 5$ glass-ceramics was 
augmented up to $60 \%{ }^{5}$ In addition, no further noticeable changes were observed to take place as the crystallization proceeded until its completion. Filho et al. ${ }^{\mathbf{5}}$ stressed the positive role played by the residual amorphous phase in the control of the ion exchange rate at the substrate-SBF interface. ${ }^{5}$

In contrast to previous findings, the occurrence of crystallization phenomena in 45S5 Bioglass ${ }^{\circledR}$ was recently reported to improve the biological response of samples soaked in acellular SBF. ${ }^{6}$ More specifically, calcium silicate and calcium carbonate, rather than HCA, were the only phases detected on the surface of 45S5 amorphous bioglass after storage in SBF up to 14 days. On the other hand, the formation of an apatite layer was clearly evidenced in crystallized samples obtained after heat-treatment at $1000{ }^{\circ} \mathrm{C}$ of the original (amorphous) material. Analogously, the presence of fine crystals in 45S5 Bioglass ${ }^{\circledR}$ samples, obtained by Spark Plasma Sintering (SPS) at $600^{\circ} \mathrm{C}$, was found to promote the formation of HCA during in-vitro tests in SBF, compared to fully amorphous specimens produced with the same technique at $550{ }^{\circ} \mathrm{C}^{7}$

Other than controversial, the previously cited studies did not provide quantitative information on the amount of HCA formed during the in-vitro tests. This holds also generally true when considering the structural characteristics of the starting samples, e.g. crystallite sizes, crystallization degree, etc., before and in the course of biological experiments.

The scope of the present investigation is then to provide a useful contribution along this direction. To this aim, commercial 45S5 Bioglass ${ }^{\circledR}$ are first spark plasma sintered to produce three series of fully dense samples with different crystallization degree, crystallites size, and composition. The adopted SPS conditions are chosen on the basis of the results obtained in a recent study where the sintering behavior of the same kind of bioglass powders was investigated. ${ }^{8}$ The resulting $45 \mathrm{~S} 5$-based products are then stored for different time intervals (0-14 days) in SBF. The biological response provided by the three groups of materials is subsequently examined by properly monitoring their weight, compositional and 
morphological changes during the test. It should be noted that, to the best of our knowledge, the quantitative evaluation of the amount and crystallites size of apatite and other phases formed during the in-vitro test, or originally present in the substrate, is performed for the first time in the literature. In addition, all the modifications taking place on the surface of the different bioglass substrates will be associated with the corresponding variations in $\mathrm{pH}$ and ions concentration of the SBF solution to which specimens were exposed.

\section{Experimental Materials and Methods}

\subsection{Preparation of Bioglass disks}

Bioglass ${ }^{\circledR}$ 45S5 Glass Spheres (Cod. GL0160P, Mo-Sci Corp., USA) were consolidated under vacuum conditions (20 Pa) by Spark Plasma Sintering (SPS 515S model, Fuji Electronic Industrial Co., Ltd., Kanagawa, Japan) to produce dense cylindrical specimens with approximately $14.7 \mathrm{~mm}$ diameter and $3 \mathrm{~mm}$ thickness. The composition of initial powders, as provided by the vendor, was $24.4 \% \mathrm{Na}_{2} \mathrm{O}, 26.9 \% \mathrm{CaO}, 46.1 \% \mathrm{SiO}_{2}$ and $2.6 \mathrm{P}_{2} \mathrm{O}_{5}(\mathrm{~mol} . \%)$. Laser light scattering analysis (CILAS 1180, France) indicated that particles size was less than $15 \mu \mathrm{m}$ with an average value of about $4.5 \mu \mathrm{m}$. Further details relative to powders characteristics and SPS experiments are reported elsewhere. ${ }^{8}$ Briefly, SPS experiments were carried out under temperature controlled mode using a K-type thermocouple (Omega Engineering Inc., USA) inserted inside a small hole drilled at the centre of the external surface of the graphite die. Fully dense samples with different crystallization degree and crystallite sizes were obtained by properly setting the dwell temperature $\left(T_{D}\right)$, holding time $\left(t_{D}\right)$ and mechanical pressure $(P)$ in the ranges $550-700{ }^{\circ} \mathrm{C}, 2$ $20 \mathrm{~min}$ and $16-70 \mathrm{MPa}$, respectively. Specifically, the three groups of 45S5-based glass specimens prepared for in-vitro tests are reported in Table $\mathbf{1}$ along with the values of the corresponding sintering parameters. 
Before using bioglass-derived products for in-vitro experiments, they were first lapped using coarse abrasive paper and then finely polished. The resulting final samples thickness was about $2.6 \mathrm{~mm}$.

The residual surface roughness in the polished samples was measured using a Form Talysurf Intra 50 profilometer (Taylor-Hobson ltd., Leicester, UK). The obtained topological data were then analysed with the Ultra Software (Taylor-Hobson, Leicester, UK). The evaluation of roughness parameters was carried on 4 different profiles for each sample. In particular, the roughness parameter $R a$, defined as the arithmetic average of the deviation of peak heights and valleys of the roughness profile from the mean line, was determined.

\subsection{SBF experiments}

To evaluate their bioactivity, the spark plasma sintered bioglass samples were subjected to in-vitro tests following the Kokubo protocol. ${ }^{9}$ Accordingly, $1000 \mathrm{~mL}$ of acellular SBF was prepared by adding $8.035 \mathrm{~g}$ of $\mathrm{NaCl}, 0.355 \mathrm{~g}$ of $\mathrm{NaHCO}_{3}, 0.225 \mathrm{~g}$ of $\mathrm{KCl}, 0.231 \mathrm{~g}$ of $\mathrm{K}_{2} \mathrm{HPO}_{4} \cdot 3 \mathrm{H}_{2} \mathrm{O}, 0.311 \mathrm{~g}$ of $\mathrm{MgCl}_{2} \cdot 6 \mathrm{H}_{2} \mathrm{O}, 39 \mathrm{~mL}$ of $1 \mathrm{M} \mathrm{HCl}, 0.292 \mathrm{~g}$ of $\mathrm{CaCl}_{2}, 0.072 \mathrm{~g}$ of $\mathrm{Na}_{2} \mathrm{SO}_{4}, 6.118 \mathrm{~g}$ of Tris hydroxymethylaminomethane and $0-5 \mathrm{~mL}$ of $1 \mathrm{M} \mathrm{HCl}$ to distilled water. The solution was then buffered at $\mathrm{pH}=7.4 \mathrm{using} 1 \mathrm{M} \mathrm{HCl}$.

During the test, each specimen was stored in $45.93 \mathrm{~mL}$ of solution $\left(\mathrm{V}_{\mathrm{s}}\right)$, that was determined according to the Kokubo procedure ${ }^{9}$, i.e.:

$$
\mathrm{V}_{\mathrm{s}}(\mathrm{mL})=\mathrm{S}_{\mathrm{a}}\left(\mathrm{mm}^{2}\right) / 10
$$

where $S_{a}$ is the apparent surface area of the sample, i.e. $459.3 \mathrm{~mm}^{2}$ in the present study. The test was conducted at $37^{\circ} \mathrm{C}$ for different time periods, namely 6 h, 1, 3, 7 and 14 days. For the sake of reproducibility, each SBF experiment was repeated at least three times.

\subsection{Characterization}

Journal of the American Ceramic Society 
After being soaked in the SBF solution, bioactive glass disks were immediately rinsed with distilled water and dried. Gravimetric measurements (Analytical balance, KERN mod. ABS 120-4, Balingen, Germany) were carried out at the end of each immersion step to determine samples weight changes during the test.

The crystalline phases initially present in the sintered samples and those ones subsequently formed after their immersion in the SBF solution were identified using a X-ray diffractometer (Philips PW 1830, Netherlands) equipped with a Ni filtered $\mathrm{Cu} \mathrm{K}_{\alpha}$ radiation $(\lambda=1.5405 \AA)$. A Rietveld analytical procedure was utilized to estimate the relative amount of the diverse phases originally present or formed during the test on the material surface as well as the related average crystallites size. ${ }^{10-12}$

The microstructure and compositional modifications taking place on the specimens surface were examined by high resolution scanning electron microscopy (HRSEM) (mod. S4000, Hitachi, Tokyo, Japan) equipped with a UltraDry EDS Detector (Thermo Fisher Scientific, Waltham, MA, USA).

Raman scattering measurements were carried out in backscattering geometry using a $632.8 \mathrm{~nm}$ line by He-Ne Laser. Measurements were performed at room temperature with a triple spectrometer Jobin-Yvon Dilor integrated system with a spectral resolution of about 1 $\mathrm{cm}^{-1}$. Spectra were recorded in the Stokes region by a 1200 groove/mm grating monochromator and a LN cooled charge coupled device (CCD) detector system.

To better evidence the impact produced at relatively longer time intervals by the interaction of the three bioglass systems with the surrounding solution, the latter one was not renewed during the entire period of soaking. Thus, $\mathrm{pH}$ and the concentration of some important species present in the solution $(\mathrm{Ca}, \mathrm{P}, \mathrm{Si}, \mathrm{Na})$ were monitored at the prescribed immersion time ends. The latter analysis was carried out by means of Inductively Coupled Plasma Optical Emission Spectroscopy (ICP-OES CCD Simultaneous, Vista - MPX Varian, Mulgrave, Australia). 


\section{Results and discussion}

\subsection{Fabrication of bioglass samples}

The less severe SPS conditions identified in a recent study to achieve the full densification of the $45 \mathrm{~S} 5$ bioglass powders used in present work were $T_{D}=550{ }^{\circ} \mathrm{C}, t_{D}=2$ min, and $P=70 \mathrm{MPa}^{8}$ The resulting sintered material mainly maintained its original glassy nature although the formation of a Na-Ca-silicate crystalline phase was also evidenced by the XRD analysis. This glass-ceramic biocomposite, indicated as 45S5_S1 in Table 1, represents the base systems tackled in this work for SBF tests. In addition, to highlight the possible effects of devitrification from the parent glass on the apatite formation during in-vitro experiments, the SPS temperature and processing time were increased to generate the two additional sets of bioceramics listed in Table 1 as 45S5_S2 and 45S5_S3. To produce the latter group of products, it should be noted that the applied pressure was lowered from 70 to $16 \mathrm{MPa}$ to avoid sample breakage due to the excessive thermo-mechanical stresses established during the sintering process.

\subsection{SBF experiments}

\subsubsection{Samples surface: XRD analysis}

The compositional and microstructural modifications occurring on the surface of the bioglass disks during in-vitro tests are first examined by XRD analysis. The Rietveld method was used to evaluate the relative content of the different phases present and the corresponding crystallites size. The experimental patterns (red rhombohedral) and the corresponding best-fit (dark line) related to 45S5_S1 samples are reported in Figure 1. In addition, the obtained average crystallites size, microstrain and relative phases amount are summarized in Table 2.

The first pattern, named "original powders", corresponds to an amorphous glass, heretoafter indicated as "amorphous 45S5" in Table 2, and is computed using a pseudo-crystalline 
structure factor $\left(\mathrm{Ca}_{1.5} \mathrm{Na}_{2.64} \mathrm{Si}_{9} \mathrm{O}_{3}\right.$, card n. 01-078-1650 of the ICDD database, crystallite size: $20 \AA$, microstrain: 0.03 ) according to the LeBail approach. ${ }^{13-15}$

The pattern indicated in Figure 1 as $t=0 d$, corresponding to the dense product obtained by SPS under the conditions reported in Table 1 for 45S5_S1, shows the presence of an amorphous phase (75 wt.\%) together with Bragg reflections ascribable to $\mathrm{Ca}_{1.5} \mathrm{Na}_{2.64} \mathrm{Si}_{9} \mathrm{O}_{3}(25$ wt.\%). The deconvolution profiles of the pattern corresponding to $t=0 \mathrm{~d}$ can be better visualized in Figure 2. It is apparent that a partial crystallization of the amorphous matrix occurs during the heat treatment process, although nanostructured domains (90 $\AA$ ) of $\mathrm{Ca}_{1.5} \mathrm{Na}_{2.64} \mathrm{O}_{9} \mathrm{Si}_{3}$, indicated as " nanocrystalline 45S5", are preserved after SPS.

The XRD analysis of the 45S5_S1 sample after $6 \mathrm{~h}$ in contact with the SBF solution evidenced some changes in the composition and surface microstructure with respect to the original ones. In particular, the peaks relative to the crystalline phase initially present in the sintered disk disappeared from the pattern. Moreover, after 1 day into SBF solution (pattern $\mathrm{t}$ $=1 \mathrm{~d}$ ), the system undergoes a further amorphization, as evidenced by the background increasing in the angular $2 \theta$ range $20-30^{\circ}$. On the other hand, reflections ascribable to nano hydroxyapatite (card n. 00-024-0033 of the ICDD database) are clearly distinguishable in the pattern referred as $\mathrm{t}=3 \mathrm{~d}$. Correspondingly, as reported in Table 2, nanodomains of around $15 \mathrm{~nm}$ are estimated for the apatite phase.

After 7 days, the amount of hydroxyapatite still increased up to 9 wt.\%. It is important to highlight that the sample shows a moderate texture with a preferred orientation corresponding to the reflection $002\left(25.84^{\circ}\right)$ : the hydroxyapatite formed onto amorphous glass nucleates or grows with (002) oriented. This aspect is better emphasized in the sample stored for 14 days, where the peak (002) presents a unexpected intensity. Finally, the amount of nano apatite increases up to $15 \mathrm{wt} . \%$ with respect to amorphous matrix.

The experimental patterns and the best-fit profiles of the 45S5_S2 samples, are reported in Figure 3, while the corresponding compositional and structural data are 
summarized in Table 3. As indicated in Table 1, relatively higher temperature, with respect to the 45S5_S1 case, were adopted to produce this class of samples. Such more severe annealing conditions are responsible for the drastic changes produced in the microstructure of the 45S5 glass, as evinced in the pattern reported in Figure 3 (pattern $t=0 \mathrm{~d}$ ). No amorphous phases can be detected in this pattern, supporting the almost complete crystallization event occurred to the glass during the SPS process for $2 \mathrm{~min}$ at the temperature of $600{ }^{\circ} \mathrm{C}$. However, as shown in Table 3, Rietveld analysis on the XRD pattern reveals that the crystallites size do not overcome $200 \AA$. As for the previous system, the Rietveld procedure confirmed that the composition of this phase is $\mathrm{Ca}_{1.5} \mathrm{Na}_{2.64} \mathrm{O}_{9} \mathrm{Si}_{3}$.

In accordance with the behavior displayed by the 25 wt. $\%$ crystallized system, the surface of 45S5_S2 samples also undergoes to a progressive amorphization when in contact with the SBF solution up to 1 day. Nonetheless, as the immersion time was prolonged to 3 days, the XRD analysis provided an unequivocal indication of the apatite formation. Specifically, under such condition, three main phases were detected in the sample, i.e. amorphous glass (65 wt.\%), nanocrystalline 45S5 (20 wt.\%) and nanohydroxyapatite (15 wt.\%). The amount of apatite was found to increase up to $21 \mathrm{wt} . \%$ in samples stored for 7 days, and a further raise of the apatite phase content (25 wt.\%) was recorded in specimens immersed for 14 days into SBF solution. Another aspect evidenced by the Rietveld analysis (cf. Table 3) is that crystallites size of nanocrystalline 45S5 decreases from 20 to $13 \mathrm{~nm}$ during the course of the test.

As reported in Table 1, the third group of samples (45S5_S3) was produced by SPS by increasing both the dwell temperature and holding time to $700{ }^{\circ} \mathrm{C}$ and $20 \mathrm{~min}$, respectively. Correspondingly, the amorphous phase crystallizes with a trigonal habitat and space group R-3m:H. In particular, this system shows crystallites size for the $\mathrm{Ca}_{1.5} \mathrm{Na}_{2.64} \mathrm{O}_{9} \mathrm{Si}_{3}$ phase of $900 \AA$, larger with respect to those ones present in the 45S5_S2 material. Moreover, a series of new peaks ascribable to an additional phase with rhenanite-type structure were 
also detected (Figure 4, $\mathrm{t}=0 \mathrm{~d}$ ). In this work, these peaks are attributed to rhenanite $\left(\mathrm{NaCaPO}_{4}\right.$, card n. 29-1193 of the ICDD database), albeit it should be noted that they might also be associated with silicorhenanite $\left(\mathrm{Na}_{2} \mathrm{Ca}_{4}\left(\mathrm{PO}_{4}\right)_{2} \mathrm{SiO}_{4}\right)$, which is the formulation generally indicated in the literature for the crystalline phase formed when of 45S5 bioactive glass are heat treated at temperature above $800^{\circ} \mathrm{C} .{ }^{16}$ All the parameters obtained by the fit analysis are reported in Table 4.

Also for the case of the 45S5_S2 samples family, a partial amorphization of the material surface preceded the formation of the apatite phase during in-vitro test in SBF. Specifically, 10 wt. \% was the content of apatite revealed after 3 days. As the immersion time was prolonged to 7 days, a further progress in the amorphization of the material surface was observed in parallel to a higher amount (25 wt.\%) of apatite. Finally, the latter phase increased to $33 \mathrm{wt} . \%$ after 14 days in contact with the SBF solution.

Analogously to the 45S5_S2 system (cf. Table 3), Rietveld data relative to 45S5_S3 (cf. Table 4) also evidence that the initial crystallites size of nanocrystalline 45S5 (90 nm) is reduced during the test in SBF, mostly within three days from the beginning of samples storage, to approach values in the range $15-18 \mathrm{~nm}$.

For the sake of comparison, the time profiles showing the relative content of apatite, as estimated through the Rietveld procedure for the three classes of bioglass products, are reported in Figure 5.

\subsubsection{Samples surface: SEM observation and EDX analysis}

To better assess the compositional and morphological changes taking place on the glass-ceramic composite samples during in-vitro tests, particularly for relatively short immersion time intervals (up to 3 days), the surfaces of the three groups of products were examined in detail by SEM and EDX. The obtained results are reported in Figures 6-8. The SEM micrographs shown in Figure $\mathbf{6 b}$ indicated that the specimens after $6 \mathrm{~h}$ immersion in SBF appeared fractured (45S5_S1 and 45S5_S2) or otherwise degraded (45S5_S3) on their 
surfaces. In any case, no evidence of the formation of new crystalline phases could be detected at this stage by SEM. However, the EDX analysis evidenced a significant change in the surface composition (cf. Figure 7). In particular, the relative content of $\mathrm{Na}$ and Si rapidly decreased from the original value, albeit it did not drop to zero after 6h storage. In parallel, the percentages of $\mathrm{Ca}$ and $\mathrm{P}$ markedly increased, particularly when considering the 45S5_S2 system. It should be noted that, during such short time period, the $\mathrm{Ca} / \mathrm{P}$ atomic ratio strongly decreased from the original value of about 5.2 to approximately 1.5. As shown in Figure 6c, the SEM micrograph relative to 45S5_S1 samples stored in SBF for $24 \mathrm{~h}$ evidenced the presence of aggregated grains, approximately round shaped, on the bioglass surface. A different situation is encountered when the 45S5_S2 sample was tested under the same conditions. Indeed, in the latter case, the entire surface was almost wholly covered by a uniform and fine layer, with a trabecular bone-like structure. The latter phase is also present, although only barely detectable by SEM, on the surface of 45S5_S3 samples. The EDX analysis results reported in Figure 7 are quite consistent with the SEM observations. In particular, after 1 day storage, Si completely disappeared, Na further decreased while the relative contents of both $\mathrm{Ca}$ and $\mathrm{P}$ still increased. Correspondingly, a value for the $\mathrm{Ca} / \mathrm{P}$ atomic ratio in the range 1.5-1.6 resulted for all the three 45S5-based systems. SEM results relative to samples contacted for 3 days with SBF confirmed that a relatively large amount of the new phase was present on the surface of 45S5_S2 materials. The microstructure and composition of the latter one was examined in detail at higher magnifications, as shown in Figure 8. The reported micrograph indicates that this phase displays a trabecular-like morphology. Moreover, based on the EDX spectra, it basically consists of $\mathrm{Ca}, \mathrm{P}$ and $\mathrm{O}$ with traces of $\mathrm{Na}$ and $\mathrm{C}$. It should be noted that the small $\mathrm{C}$ signal appearing in the EDX spectra could be either due to the carbonation of the apatite layer but also to graphite used to guarantee the electric conduction of samples observed by SEM. Nonetheless, the issue related to the apatite carbonation will be clarified in next section taking advantage of Raman 
spectroscopy. On the other hand, the small $\mathrm{Na}$ signal is likely ascribable to the sample underneath the apatite layer. The EDX analysis revealed also that, as the soaking time was increased, the $\mathrm{Ca}$ and $\mathrm{P}$ at.\% reached a maximum value and then slightly decreased, whereas an opposite behavior was correspondingly observed for $\mathrm{O}$. In parallel, the $\mathrm{Ca} / \mathrm{P}$ atomic ratio only slightly changed to finally reach an approximate value of about 1.6.

\subsubsection{Samples surface: Raman analysis}

The apatite phase formed on the surface of 45S5 samples during the SBF test was further characterized by Raman spectroscopy. As an example, Figure 9 reports the Raman spectrum in the region between 900 and $1150 \mathrm{~cm}^{-1}$ relative to the 45S5_S2 sample soaked for a 3 days into the SBF solution. For comparison, that one relative to pure apatite is also shown.

Apatite reports several bands in this spectra region related to the phosphate Raman ones. In particular, the main peak at $965 \mathrm{~cm}^{-1}$ is assigned to the $v_{1}$ mode while the lower peaks in the region around $1050-1080 \mathrm{~cm}^{-1}$ are connected to the triply degeneration of the $v_{3}$ modes. ${ }^{17}$

The peak related to $v_{1}$ mode of carbonate appears at about $1070 \mathrm{~cm}^{-1}$.In this regard, it has been already observed in the literature ${ }^{18-19}$ that even small amounts of carbonate generate large variation in the Raman spectrum of apatite samples with a large broadening of the $v_{3}$ phosphate modes and the presence of the additional carbonate band. Moreover, if the amount of carbonate is above $3 \mathrm{wt} \%$, the contribution of the $v_{1}$ mode of carbonate mode overlaps the phosphate modes, thus avoiding a clear identification of the different degenerate features. In this view and according to Awonusi et al. ${ }^{18}$, the spectra of the carbonated apatite sample can be well fitted with three Gaussian: a first contribution at about $960 \mathrm{~cm}^{-1}$ related to the phosphate, a broad band at about $1050 \mathrm{~cm}^{-1}$, that takes into account the $v_{3}$ modes, and a broad signal at about $1070 \mathrm{~cm}^{-1}$ related to $\mathrm{CO}_{3}^{2-} v_{1}$ mode (cf. Figure 9). Hence, a rough estimation of the carbonated content can be obtained from the ratio between the area of the $1070 \mathrm{~cm}^{-1}$ carbonate band and the $960 \mathrm{~cm}^{-1}$ phosphate contribution; in our analysis a ratio of 0.27 has 
been obtained which corresponds to about $8 \mathrm{wt} \%$ of carbonate content, according to Awonusi et al.. ${ }^{18}$ In conclusion, the Raman spectroscopy unequivocally confirmed that the formed phosphate phase consisted of carbonated hydroxyapatite (HCA).

\subsubsection{Sample weight loss}

Weight changes data of the three 45S5 groups of bioglass specimens during their immersion in the SBF solution are plotted in Figure 10. The obtained results indicate that mass losses, due to sample dissolution, always prevailed with respect to the corresponding gain, caused by the new phases formation on the materials surface. In addition, it is observed that dissolution phenomena are mainly confined to the first day of immersion, while they tends to become less important as the soaking time is progressively augmented. When the behavior of the three series of specimens is compared, it can be stated that weight loss takes place in the following order 45S5_S1 >> 45S5_S2 > 45S5_S3. In particular, the obtained data clearly indicated that, during the in-vitro test, the samples consisting of the $75 \mathrm{wt} . \%$ of the glassy phase lose their mass almost twice with respect to the fully crystallized counterparts.

\subsubsection{Changes in the SBF solution}

The time-evolution of $\mathrm{pH}$ in the SBF solution during the test is shown in Figure 11. For all the three bioglass systems, which exhibited a similar (qualitative) behavior, this parameter increases monotonically from its initial value. In addition, the major changes take place during the first three days of immersion in the $\mathrm{SBF}$, while minor variations are observed as the test proceeds. In any case, $\mathrm{pH}$ did not overcome the value of 8 . Nonetheless, in correspondence to the prescribed storage time intervals, relatively higher $\mathrm{pH}$ were obtained according to the following order 45S5_S1 > 45S5_S2 > 45S5_S3.

The latter hierarchy holds also generally true when the differences between the concentration of some of the more relevant species present in the solution with respect to the initial values, 
are compared for the three bioglass groups, as reported in Figure 12. Firstly, it is seen that the main changes take place within 3 days from the beginning of the test. In addition, $\mathrm{Ca}$ and $\mathrm{Si}$ released were found relatively higher for 45S5_S1, whereas slightly superior $\mathrm{Na}$ concentration was revealed for the 45S5_S3 system. The data relative to the P content plotted in Figure 12 display a monotonically decreasing behavior, for all groups of 45S5 samples, during the progress of the in-vitro test. Furthermore, a relatively higher depletion rate of $\mathrm{P}$ from the solution, particularly up to 3 days immersion, was detected when considering the 45S5_S2 samples.

\section{Discussion}

As mentioned in the Introduction section, the response of bioactive materials during invitro tests depends not only by the nominal composition of the system, i.e. that one of classical Bioglass ${ }^{\circledR}$ for the present study, but also by several other factors. In particular, the relative density of bulk materials, topological aspects (surface roughness), type and content of crystallized phases formed during powders processing, crystallization degree, crystallites size, etc., also affect the interaction between the material and the physiological solution. Therefore, the discussion of the results obtained during in-vitro experiments in this investigation has to be preceded by an accurate analysis of the samples characteristics prior the biological test.

Since the main scope of this work is to highlight the consequences arising from the use of differently crystallized bioactive glasses on the apatite formation, the other possibly affecting features, particularly material porosity and surface roughness, have been minimized. In this regard, it should be first noted that the three groups of 45S5-based specimens considered for biological tests are completely dense. This outcome was confirmed by SEM observation of the corresponding cross sections, whose results are not reported here for the sake of brevity. In addition, before their immersion in the SBF solution, all samples were 
finely polished, so that the resulting residual roughness was very low. To support the latter statement, it should be noted that the measured values of the Ra parameter for the 45S5_S1, 45S5_S2 and 45S5_S3 specimens were $0.046 \pm 0.012,0.045 \pm 0.006$, and $0.036 \pm 0.006 \mu \mathrm{m}$, respectively. Of course, the roughness property will be unavoidably modified during samples immersion in the SBF solution due to the occurrence of dissolution phenomena and the deposition of new phases on the material surface.

As described in the previous section, the microstructural characteristics of the three different classes of sintered disks are consistent with the corresponding SPS parameters adopted to consolidate the bioglass powders (cf. Table 1). Specifically, when the latter ones were processed under the milder temperature $\left(550{ }^{\circ} \mathrm{C}\right)$ and holding time $(2 \mathrm{~min})$ conditions required, with an applied pressure of $70 \mathrm{MPa}$, to achieve their complete densification, about $75 \mathrm{wt} \%$ of the 45S5_S1 material preserved its original amorphous nature. On the other hand, the remaining fraction underwent devitrification during the heat treatment, to generate $9 \mathrm{~nm}$ sized nanocrystallites, whose composition was ascertained by the fitting procedure as $\mathrm{Ca}_{1.5} \mathrm{Na}_{2.64} \mathrm{Si}_{9} \mathrm{O}_{3}$. In this regard, it should be noted that the use of the Rietveld approach allowed us to identify a more precise formulation for the crystalline phase formed from the glass with respect to that one $\left(\mathrm{Na}_{2} \mathrm{Ca}_{2} \mathrm{Si}_{3} \mathrm{O}_{9}\right)$ indicated in our previous study ${ }^{8}$ and reported in prior investigations addressed to $45 \mathrm{~S} 5$ bioglass processing either by $\mathrm{SPS}^{20}$ or using alternative heat treatment methods. ${ }^{5-6,21-22}$ Moreover, additional formulations, for instance $\mathrm{Na}_{2} \mathrm{CaSi}_{2} \mathrm{O}_{6}{ }^{7}$ or $\mathrm{Na}_{2} \mathrm{CaSi}_{3} \mathrm{O}_{8}{ }^{23}$, were also attributed to the crystallized phases formed in $45 \mathrm{~S} 5$ bioactive glasses during SPS. The difficulty in identifying the precise composition for such sodium-calcium-silicate is ascribed to the fact that all these phases not only display similar XRD patterns but are also prone to generate solid-solid solutions. ${ }^{24}$ In addition, the specific crystalline phase formed from 45S5 bioglass could also depend on particle size of original powders as well as the conditions adopted during heat treatment. ${ }^{24}$ In any case, the $\mathrm{Ca}_{1.5} \mathrm{Na}_{2.64} \mathrm{O}_{9} \mathrm{Si}_{3}$ composition was used in this work as it allowed us to reproduce more 
satisfactorily, with respect to the alternative silicate phases mentioned above, the XRD patterns of the SPSed samples taken into account.

As shown in Figure 3 and summarized in Table $3(t=0 \mathrm{~d})$, the slight augment of $50{ }^{\circ} \mathrm{C}$ in the dwell temperature, while maintaining the other SPS parameters unchanged, was anyhow sufficient to determine the crystallization completion from the glass phase as well an increase of the $\mathrm{Ca}_{1.5} \mathrm{Na}_{2.64} \mathrm{Si}_{9} \mathrm{O}_{3}$ crystallites size to $20 \mathrm{~nm}$ (45S5_S2). Finally, as the $\mathrm{T}_{\mathrm{D}}$ and $\mathrm{t}_{\mathrm{D}}$ values were both raised to $700^{\circ} \mathrm{C}$ and $20 \mathrm{~min}$, respectively, to produce the $45 \mathrm{S5}$ S 3 series of specimens, grains growth proceeded up to $90 \mathrm{~nm}$ (Table 4). Furthermore, in addition to the silicate phase, about 15 wt.\% of $\mathrm{NaCaPO}_{4}$ with $80 \mathrm{~nm}$ grains sized was also formed during SPS in the latter group of samples.

Before examining the results obtained in the present work relatively to the behavior displayed by these three groups of samples during in-vitro tests, some preliminary considerations are worth to be made. In particular, it should be mentioned that the physiological media used in various studies reported in the literature were periodically refreshed. ${ }^{25-27}$ Such choice was aimed to maintain the ions concentration more stable during the test. Relatively higher $\mathrm{Ca}$ and $\mathrm{P}$ amounts are consequently made available in the SBF solution, so that more favorable conditions for the formation of the apatite layer on the bioglass surface can be established. Alternatively, according to the procedure followed by other authors, ${ }^{6,28-29}$ the SBF solution was not renewed during the course of the biological test conducted in the present work. The reason for that is to better highlight the different outcomes correspondingly produced, which might not be so apparent, particularly as far as the changes in the solution are concerned, if the SBF is frequently replaced.

Results relative to SBF experiments will be then analyzed. The data plotted in Figure 10 testify the superior weight loss manifested by the 45S5_S1 category of samples. This outcome can be readily associated with the primary amorphous nature of such system, which makes it more reactive, with respect to the fully crystalline 45S5_S2 and 45S5_S3 ones, 
when in contact with the solution. In addition, although the latter two groups of specimens displayed similar dissolution behavior, the 45S5_S2 samples decreased their weight markedly during the first week storage in SBF, as compared to 45S5_S3 ones. It is likely that the relatively larger grains boundary area made available by the presence of finer grains in the first kind of material justifies its preferential dissolution with respect to the second, coarser, one. It is also possible that the presence of rhenanite might play a role in this regard.

The chemical changes observed in the SBF solution are quite in agreement with the corresponding dissolution behavior and could be interpreted on the basis of the mechanism proposed in the literature for the apatite formation in bioactive glasses. ${ }^{3}$ Firstly, the rapid increase of $\mathrm{pH}$ and concentration cations manifested by all groups of samples (cf. Figures 11 and 12) is a logical consequence of initial phenomena taking place at the glass-SBF solution interface, which involve the ion exchange of $\mathrm{Ca}^{2+}$ and $\mathrm{Na}^{+}$(material $\rightarrow$ solution) with $\mathrm{H}^{+}$ (solution $\rightarrow$ glass surface). ${ }^{3}$ The more significant $\mathrm{pH}$ increase and Ca release taking place for the 45S5_S1 system, followed by the 45S5_S2 and, finally, 45S5_S3 series of samples, is consistent with the dissolution character they exhibited. Also Si concentration profiles followed the same behavior. The only exception is represented by the preferential Na release observed for the case of 45S5_S3 products (cf. Figure 12), particularly at relatively short immersion times. In this regard, the presence of $\mathrm{NaCaPO}_{4}$ previously postulated could explain the dissolution behavior displayed by the latter class of materials. Therefore, it could also likely influence the selective ions release during the in-vitro test.

Besides, the comparison of the three series of bioglass samples relatively to the apatite formation is even more important. Surprisingly, different situations are encountered depending upon the immersion time taken into account. In particular, the results shown in Figure 5 for systems immersed for three days in SBF evidenced that the amount of apatite varies in the following decreasing order: 45S5_S2 > 45S5_S3 > 45S5_S1. The latter outcome was confirmed by SEM observations (Figure 6d) coupled with EDX analysis (Figure 7). 
Due to the detection limit of the XRD analysis, no reliable data on the apatite formation could be provided by the Rietveld procedure for storage time periods equal or shorter than 1 day. Nonetheless, the generation of the new phase after 1 day immersion was assessed by SEM (Figure 6c). Moreover, the related results also confirmed that more favorable conditions for the formation of a homogeneous apatite layer are established when considering the 45S5_S2 samples. This statement is further supported by the correspondingly more drastic reduction of P concentration in SBF (Figure 12), in particular for soaking times equal or shorter than 1 day. Indeed, the faster formation of the HCA layer on the surface of 45S5_S2 materials, has to be necessarily accompanied by a quicker consumption of the $\mathrm{P}$ species in the SBF solution. On the basis of the obtained results, it is therefore possible to state that, among the three groups of 45S5-based bioceramics considered in this work, the fully crystallized samples exclusively consisting of $\mathrm{Ca}_{1.5} \mathrm{Na}_{2.64} \mathrm{Si}_{9} \mathrm{O}_{3}$ grains with average size of about $20 \mathrm{~nm}$ display superior capability to more rapidly produce larger amounts of apatite within three days storage.

However, a slightly diverse situation was encountered when the contact period of the materials with the SBF solution was extended. Indeed, the surface of 45S5_S3 samples immersed for 7 and 14 days was relatively richer in HCA with respect to the other systems. As previously highlighted, the presence of rhenanite in this class of bioglass products was found to affect their interaction with SBF. In this regard, the lower mass loss they generally displayed (cf. Figure 10), and the corresponding less significant $\mathrm{pH}$ increase (cf. Figure 11), are expected to play a positive role in establishing more favorable conditions for HCA formation and its preservation on the bioceramic surface at relatively longer immersion times. Nonetheless, Figure 5 still confirmed a lower amount of apatite on the surface of the 75 wt.\% amorphous samples with respect to the other two groups of specimens.

Therefore, the generation of the HCA layer is always preferably promoted in fully crystallized samples with respect to the glass-ceramic 45S5_S1 group, where the amorphous 
fraction prevails. These findings are then in contrast with the results obtained by Li et al. ${ }^{4}$ and Filho et al. ${ }^{\mathbf{5}}$, who emphasized the negative effects produced by the bioglass crystallization on the apatite formation. The different bioglass formulation and physiological solution $^{4}$ and/or annealing method/conditions adopted to induce crystallization from the parent glass $^{5}$ are possibly responsible for the observed discrepancies with respect to the present study. On the other hand, our findings seem to be more consistent with those ones reported in recent studies where conventional sintering ${ }^{6}$ or the SPS method $^{7}$ were used to promote the devitrification of 45S5 bioglass. In particular, Grasso et al. $^{7}$ found that the formation of HCA during in-vitro tests in SBF was facilitated by the presence of fine $\mathrm{Na}_{2} \mathrm{CaSi}_{2} \mathrm{O}_{6}$ crystals in dense samples obtained by SPS at $600{ }^{\circ} \mathrm{C}{ }^{7}$ However, the different sintering conditions and characterization methods adopted in the latter two studies were not sufficient to evidence the experimental findings described in the present work from a quantitative point of view.

Some considerations to possibly explain the peculiar behavior exhibited by 45S5_S2 and 45S5_S3 samples will be finally made taking advantage of the mechanism of interaction recently proposed by Boccaccini et al. ${ }^{22}$ for Bioglass ${ }^{\circledR}$ based glass-ceramics in SBF. First of all, it was postulated that during storage the crystalline grains break-down through preferential dissolution at crystal structural defects. This fact is consistent with the progressive reduction of crystallites size evidenced in both systems by the Rietveld analysis. In addition, the fact that ion-exchange is expected to take place preferably at the grains boundaries likely explains the larger amount of apatite formed during the first 3 days immersion on the surface of 45S5_S2 samples, which exhibit relatively smaller crystallites size with respect to 45S5_S3 specimens. On the other hand, as shown in Tables 3-4, the progressive crystallites refinement makes their size in the two class of biomaterials roughly similar, i.e. 13 and $15-18 \mathrm{~nm}$, so that the latter effect tends to vanish as the immersion time was increased. Under such circumstances, the presence of rhenanite-type ceramic makes the 
only relevant difference between the two systems. Thus, it is likely that this phase is responsible for the improved HCA formation. In this regard, it should be noted that in-vivo experiment involving various calcium phosphates including rhenanite, evidenced the capability of the latter phase to be transformed completely into apatite. ${ }^{30}$ The progressively decrease of rhenanite content during the in-vitro test conducted in the present work (cf. Table 4) supported the latter statement.

\section{Concluding remarks}

The biological response of three series of bioceramics obtained by SPS from 45S5 Bioglass powders was examined in detail. As revealed by the Rietveld analysis of the related XRD patterns, about 25 wt. $\%$ of the material underwent devitrification under the milder SPS conditions $\left(550{ }^{\circ} \mathrm{C}, 2 \mathrm{~min}\right)$ adopted to achieve the full powder densification in the first group of samples. The resulting crystalline phase $\left(\mathrm{Ca}_{1.5} \mathrm{Na}_{2.64} \mathrm{Si}_{9} \mathrm{O}_{3}\right)$ exhibits approximately $9 \mathrm{~nm}$ sized grains. The second class of 45S5-derived materials was obtained by increasing the dwell temperature to $600^{\circ} \mathrm{C}$. Correspondingly, the crystallization process from the parent glass went to completion accompanied by grains growth to $20 \mathrm{~nm}$. Finally, the third category of bioglasses was produced under the most severe SPS conditions here investigated $\left(700^{\circ} \mathrm{C}\right.$, $20 \mathrm{~min}$ ) which determined not only a further increase of crystallites size $(90 \mathrm{~nm})$, but also the formation of a new phase characterized by a rhenanite-like structure, ascribed to $\mathrm{NaCaPO}_{4}$, whose content was estimated of approximately $15 \mathrm{wt} . \%$.

The in-vitro tests results involving the interaction of these samples with acellular SBF are briefly summarized in what follows:

a) within the entire immersion time period investigated, HCA formation is mostly promoted in the two series of fully crystallized samples instead of the mainly amorphous system; in addition, the latter one displayed the higher weight loss, and determined the more significant increase in $\mathrm{pH}$ and ions released; in this regard, it 
is important to note that too high $\mathrm{pH}$ levels have to be avoided as they might provoke cells damage or even their death;

b) a larger content of apatite was detected during the first 3 days immersion on the surface of specimens exclusively consisting of $\mathrm{Ca}_{1.5} \mathrm{Na}_{2.64} \mathrm{Si}_{9} \mathrm{O}_{3}$ with crystallites size of $20 \mathrm{~nm}$; such biological response is probably ascribed to the large grains boundary area made available by the presence of such nanocrystallites, which determines an intensification of ion-exchange phenomena and, in turn, the formation of the HCA layer;

c) the initial presence of the rhenanite phase in the third group of bioglass products contributes favorably to the formation of larger amounts of HCA at relatively longer storage periods.

\section{Acknowledgements}

The financial support for this work from Regione Autonoma della Sardegna (Italy), L.R. n.7/2007, CUP n. F71J11001070002, is gratefully acknowledged. One of us (L.D.) has performed his activity in the framework of the International PhD in Innovation Sciences and Technologies at the University of Cagliari, Italy. The authors thank Francesco Loy e Gabriele Conti (University of Cagliari, Italy) for their technical support. 


\section{References}

1. Hench LL. The Story of Bioglass ${ }^{\circledR}$. J Mater Sci Mater Med. 2006;17:967-978.

2. Rahaman MN, Day DE, Sonny Bal B, et al. Bioactive glass in tissue engineering. Acta Biomater. 2011;7(6): 2355-2373.

3. Jones JR. Review of bioactive glass: From Hench to hybrids. Acta Biomater. 2013;9(1):4457-4486.

4. Li P, Yang Q, Zhang F, Kokubo T. The effect of residual glassy phase in a bioactive glass-ceramic on the formation of its surface apatite layer in vitro. J. Mater. Sci. Mater. Med. 1992;3(6):452-456.

5. Filho OP, Latorre GP, Hench LL. Effect of crystallization on apatite-layer formation of bioactive glass 45S5. J. Biomed. Mater. Res. 1996;30(4):509-514.

6. Plewinski M, Schickle K, Lindner M, et al. The effect of crystallization of bioactive bioglass 45S5 on apatite formation and degradation. Dental Mater. 2013;29(12):12561264.

7. Grasso S, Chinnam RK, Porwal H, et al. Low temperature spark plasma sintering of 45S5 Bioglass ${ }^{\circledR}$. J. Non-Cryst. Solids. 2013;362(1):25-29.

8. Desogus L, Cuccu A, Montinaro S, et al. Classical Bioglass ${ }^{\circledR}$ and innovative CaO-rich bioglass powders processed by Spark Plasma Sintering: a comparative study. J Eur. Ceram. Soc. 2015;35:4277-4285.

9. Kokubo T, Takadama H. How useful is SBF in predicting in vivo bone bioactivity? Biomaterials. 2006;27:2907-2915.

10. Lutterotti L, Scardi P. Simultaneous Structure and Size-Strain Refinement by the Rietveld Method. J. Appl. Cryst. 1990;23:246-252.

11. Lutterotti L, Gialanella S. X-ray diffraction characterization of heavily deformed metallic specimens. Acta Mater. 1998;46(1):101-110. 
12. Scardi P, Lutterotti L, Maistrelli P. Experimental Determination of the Instrumental Broadening in the Bragg-Brentano Geometry. Powder Diffr. 1994;9(3):180-186.

13. Le Bail A. Modelling the silica glass structure by Rietveld method. J. Non-Cryst. Solids. 1995;183:39-42.

14. Lutterotti L, Ceccato R, Dal Maschio R, et al. Quantitative analysis of silicate glass in ceramic materials by the Rietveld method. Mater Sci Forum. 1998;278-281:87-92.

15. Baser TA, Baricco M, Enzo S, et al. Analysis of crystallization behavior of Fe48Cr15Mo14Y2C15B6 bulk metallic glass by synchrotron radiation. J. Mater. Res. 2008;23(8):2166-2173.

16. Lefebvre L, Chevalier J, Gremillard L, et al. Structural transformations of bioactive glass 45S5 with thermal treatments. Acta Mater. 2007;55:3305-3313.

17. Penel G, Leroy G, Rey C, et al. Infrared and Raman microspectrometry study of fluorfluor-hydroxy and hydroxy-apatite powders. J. Mater Sci. Mater. Med. 1997;8:271276.

18. Awonusi A, Morris MD, Tecklenburg MM. Carbonate assignment and calibration in the Raman spectrum of apatite. Calcif. Tissue Int. 2007;81:46-52.

19. Morris MD, Mandair GS. Raman Assessment of Bone Quality. Clin. Orthop. Relat. Res. 2011;469:2160-2169.

20. Chen QZ, Xu JL, Yu LG, et al. Spark plasma sintering of sol-gel derived 45S5 Bioglass ${ }^{\circledR}$-ceramics: Mechanical properties and biocompatibility evaluation. Mater Sci Eng C. 2012;32:494-502.

21. Clupper DC, Hench LL. Crystallization kinetics of tape cast bioactive glass 45S5. J. Non-Cryst. Solids. 2003;318:43-48.

22. Boccaccini AR, Chen Q, Lefebvre L, et al. Sintering, crystallisation and biodegradation behaviour of Bioglass-derived glass-ceramics. Faraday Discuss. 2007;136:27-44. 
23. Porwal H, Grasso S, Cordero-Arias L, et al. Processing and bioactivity of 45S5 Bioglass ${ }^{\circledR}$-graphene nanoplatelets composites. J. Mater. Sci. Mater. Med. 2014;25(6):1403-1413.

24. Bellucci D, Cannillo V, Sola A. An Overview of the Effect of Thermal Processing on Bioactive Glasses. Sci. Sinter. 2010;42:307-320.

25. Bellucci D, Cannillo V, Sola A, et al. Macroporous Bioglass ${ }^{\circledR}$-derived scaffolds for bone tissue regeneration. Ceram. Int. 2011;37:1575-1585.

26. Zheng K, Solodovnyk A, Li W, et al. Aging Time and Temperature Effects on the Structure and Bioactivity of Gel-Derived 45S5 Glass-Ceramics. J. Am. Ceram. Soc. $2015 ; 98: 30-38$.

27. Boccardi E, Melli V, Catignoli G, et al. Study of the mechanical stability and bioactivity of Bioglass ${ }^{\circledR}$ based glass-ceramic scaffolds produced via powder metallurgy-inspired technology. Biomed. Mater. 2016;11(1):015005.

28. Essien ER; Adams LA, Shaibu RO, et al. Economic route to sodium-containing silicate bioactive glass scaffold. Open Journal of Regenerative Medicine 2012;1(3):33-40.

29. Mačković M, Hoppe A, Detsch R, et al. Bioactive glass (type 45S5) nanoparticles: in vitro reactivity on nanoscale and biocompatibility. J. Nanopart. Res. 2012;14:966-987.

30. Driessens FCM, Ramselaar MMA, Schaeken HG, et al. Chemical reactions of calcium phosphate implants after implantation in vivo. J. Mater. Sci. Mater. Med. 1992;3(6):413-417. 
Table 1. Designation of 45S5 bioglass samples and related SPS conditions

\begin{tabular}{lccc}
\hline Sample ID & $\mathbf{T}_{\mathbf{D}}\left({ }^{\circ} \mathbf{C}\right)$ & $\mathbf{t}_{\mathbf{D}}(\mathbf{m i n})$ & $\mathbf{P}(\mathbf{M P a})$ \\
\hline 45S5_S1 & 550 & 2 & 70 \\
45S5_S2 & 600 & 2 & 70 \\
& & & \\
45S5_S3 & 700 & 20 & 16 \\
\hline
\end{tabular}

2

4

5

6

7

8

9

10

11

12

13

14

15

16

17

18

19

20

21

22

23

24

25

26

27

28

29

30

31

32

33

34

35

36

37

38

39

40

41

42

43

44

45

46

47

48

49

50

51

52

53

54

55

56

57

58

59

60

Journal of the American Ceramic Society 
Table 2. Phases and quantitative phase analysis results relatively to 45S5_S1 samples stored in the SBF for different time intervals.

\begin{tabular}{|c|c|c|c|c|}
\hline Sample & Phases & $\begin{array}{l}\text { Crystallite } \\
\text { sizes }\end{array}$ & Microstrain & wt. $\%$ \\
\hline $\begin{array}{l}\text { Original } \\
\text { powders }\end{array}$ & Amorphous 45S5 & & & 100 \\
\hline$t=0 d$ & $\begin{array}{c}\text { Amorphous } 45 \mathrm{~S} 5 / \text { nanocrystalline } \\
45 \mathrm{~S} 5\end{array}$ & $/ 90 \AA$ & $/ 1 * 10^{-3}$ & $75 / 25$ \\
\hline $\mathrm{t}=6 \mathrm{~h}$ & New amorphous phase & & & $>95$ \\
\hline$t=1 d$ & New amorphous phase & & & $>95$ \\
\hline$t=3 d$ & New amorphous phase / apatite & $/ 150 \AA$ & $/ 4 * 10^{-3}$ & $93 / 7$ \\
\hline $\mathrm{t}=7 \mathrm{~d}$ & New amorphous phase / apatite & $/ 230 \AA$ & $/ 4 * 10^{-3}$ & $91 / 9$ \\
\hline$t=14 d$ & New amorphous phase / apatite & $/ 190 \AA$ & $/ 3 * 10^{-3}$ & $85 / 15$ \\
\hline
\end{tabular}

Journal of the American Ceramic Society 
1

2

3

4

5

6

7

8

9

10

11

12

13

14

15

16

17

18

19

20

21

22

23

24

25

26

27

28

29

30

31

32

33

34

35

36

37

38

39

40

41

42

43

44

45

46

47

48

49

50

51

52

53

54

55

56

57

58

59

60

Table 3. Phases and quantitative phase analysis results relatively to 45S5_S2 samples stored in the SBF for different time intervals.

\begin{tabular}{|c|c|c|c|c|}
\hline Sample & Phases & $\begin{array}{l}\text { Crystallite } \\
\text { sizes }\end{array}$ & Microstrain & wt. $\%$ \\
\hline $\begin{array}{l}\text { Original } \\
\text { powders }\end{array}$ & Amorphous 45S5 & & & 100 \\
\hline$t=0 d$ & Nanocrystalline 45S5 & 200 & $/ 1 * 10^{-3}$ & 100 \\
\hline$t=6 \mathrm{~h}$ & $\begin{array}{l}\text { New amorphous phase/ } \\
\text { nanocrystalline } 45 \mathrm{~S} 5\end{array}$ & $/ 200$ & $/ 1 * 10^{-3}$ & $10 / 90$ \\
\hline$t=1 d$ & $\begin{array}{c}\text { New amorphous phase/ } \\
\text { nanocrystalline 45S5 }\end{array}$ & $/ 180$ & $/ 1 * 10^{-3}$ & $30 / 70$ \\
\hline$t=3 d$ & $\begin{array}{c}\text { New amorphous phase/ } \\
\text { nanocrystalline 45S5/apatite }\end{array}$ & $/ 130 / 210$ & $/ 1 * 10^{-3} / 5^{*} 10^{-3}$ & $65 / 20 / 15$ \\
\hline$t=7 d$ & $\begin{array}{c}\text { New amorphous phase/ } \\
\text { nanocrystalline 45S5/apatite }\end{array}$ & $/ 130 / 170$ & $/ 1 * 10^{-3} / 5 * 10^{-3}$ & $64 / 15 / 21$ \\
\hline$t=14 d$ & $\begin{array}{c}\text { New amorphous phase/ } \\
\text { nanocrystalline 45S5/apatite }\end{array}$ & $/ 130 / 220$ & $/ 2 * 10^{-3} / 4 * 10^{-3}$ & $65 / 10 / 25$ \\
\hline
\end{tabular}

Journal of the American Ceramic Society 
Table 4. Phases and quantitative phase analysis results relatively to 45S5_S3 samples stored in the SBF for different time intervals.

\begin{tabular}{|c|c|c|c|c|}
\hline Sample & Phases & $\begin{array}{l}\text { Crystallite } \\
\text { sizes }\end{array}$ & Microstrain & wt. $\%$ \\
\hline $\begin{array}{l}\text { Original } \\
\text { powders }\end{array}$ & Amorphous 45S5 & & & 100 \\
\hline$t=0 d$ & $\begin{array}{l}\text { Nanocrystalline } \\
\text { 45S5/rhenanite }\end{array}$ & $900 / 800$ & $2 * 10^{-3} / 4 * 10^{-3}$ & $85 / 15$ \\
\hline $\mathrm{t}=6 \mathrm{~h}$ & $\begin{array}{l}\text { New amorphous phase/ } \\
\text { nanocrystalline } 45 \mathrm{~S} 5 / \\
\text { rhenanite }\end{array}$ & $/ 900 / 700$ & $1 * 10^{-3} / 3 * 10^{-3}$ & $8 / 86 / 6$ \\
\hline$t=1 d$ & $\begin{array}{l}\text { New amorphous phase/ } \\
\text { nanocrystalline 45S5/ } \\
\text { rhenanite }\end{array}$ & $/ 600 / 650$ & $1 * 10^{-3} / 3 * 10^{-3}$ & $12 / 84 / 3$ \\
\hline$t=3 d$ & $\begin{array}{c}\text { New amorphous phase/ } \\
\text { nanocrystalline 45S5/apatite }\end{array}$ & $/ 150 / 260$ & $/ 1 * 10^{-3} / 5 * 10^{-3}$ & $60 / 30 / 10$ \\
\hline$t=7 d$ & $\begin{array}{c}\text { New amorphous phase/ } \\
\text { nanocrystalline 45S5/apatite }\end{array}$ & $/ 160 / 280$ & $/ 1 * 10^{-3} / 5 * 10^{-3}$ & $55 / 20 / 25$ \\
\hline$t=14 d$ & $\begin{array}{c}\text { New amorphous phase/ } \\
\text { nanocrystalline 45S5/apatite }\end{array}$ & $/ 180 / 131$ & $/ 1 * 10^{-3} / 1 * 10^{-3}$ & $52 / 15 / 33$ \\
\hline
\end{tabular}




\section{Captions figures}

Figure 1. XRD patterns and related Rietveld refinements of 45S5_S1 samples as a function of the immersion time in the SBF solution. Data relative to the original bioglass powders are also shown for the sake of comparison. Label $45 \mathrm{~S} 5$ refers to the $\mathrm{Ca}_{1.5} \mathrm{Na}_{2.64} \mathrm{Si}_{9} \mathrm{O}_{3}$ phase.

Figure 2. Deconvolution of the XRD pattern relative to the SPSed 45S5_S1 product before being immersed in the SBF solution.

Figure 3. XRD patterns and related Rietveld refinements of 45S5_S2 samples as a function of the immersion time in the SBF solution. Data relative to the original bioglass powders are also shown for the sake of comparison. Label 45S5 refers to the $\mathrm{Ca}_{1.5} \mathrm{Na}_{2.64} \mathrm{Si}_{9} \mathrm{O}_{3}$ phase.

Figure 4. XRD patterns and related Rietveld refinements of 45S5_S3 samples as a function of the immersion time in the SBF solution. Data relative to the original bioglass powders are also shown for the sake of comparison. Label $45 \mathrm{~S} 5$ refers to the $\mathrm{Ca}_{1.5} \mathrm{Na}_{2.64} \mathrm{Si}_{9} \mathrm{O}_{3}$ phase.

Figure 5. Temporal changes of apatite content on the surface of the three class of 45S5bioglass samples during in-vitro test, as revealed by the Rietveld analysis.

Figure 6. SEM micrographs (5000X) of the three groups of $45 \mathrm{~S} 5$ specimens at different immersion times in the SBF solution: (a) $0 \mathrm{~h}$, (b) $6 \mathrm{~h}$, (c) $1 \mathrm{~d}$, and (d) $3 \mathrm{~d}$.

Figure 7. Compositional changes, as revealed by EDX analysis, taking place on the surface of the three groups of $45 \mathrm{~S} 5$ specimens during their immersion in the SBF solution.

Figure 8. Detailed micrograph, and related EDX spectra, of the surface of 45S5_S2 sample after immersion for 3 days in the SBF solution. The EDX analysis provided the following results: Ca: 34 at. \%, P: 21 at.\%, O: 44 at. \%, and Na: 1 at.\%. The contribution of the $\mathrm{C}$ signal was not considered, due to the presence of graphite used to guarantee the electric contact in samples examined by SEM.

Figure 9. Raman spectrum of the 45S5_S2 sample immersed for 3 days in SBF. The Raman data of pure apatite is also shown for the sake of comparison. 
Figure 10. Weight changes of the three groups of $45 \mathrm{SS}$ specimens as a function of immersion times in the SBF solution.

Figure 11. Temporal evolution in $\mathrm{pH}$ of the SBF solutions where the three groups of 45S5 specimens were immersed.

Figure 12. Compositional changes of the SBF solutions where the three series of 45S5 samples were soaked up to 14 days.

Journal of the American Ceramic Society 


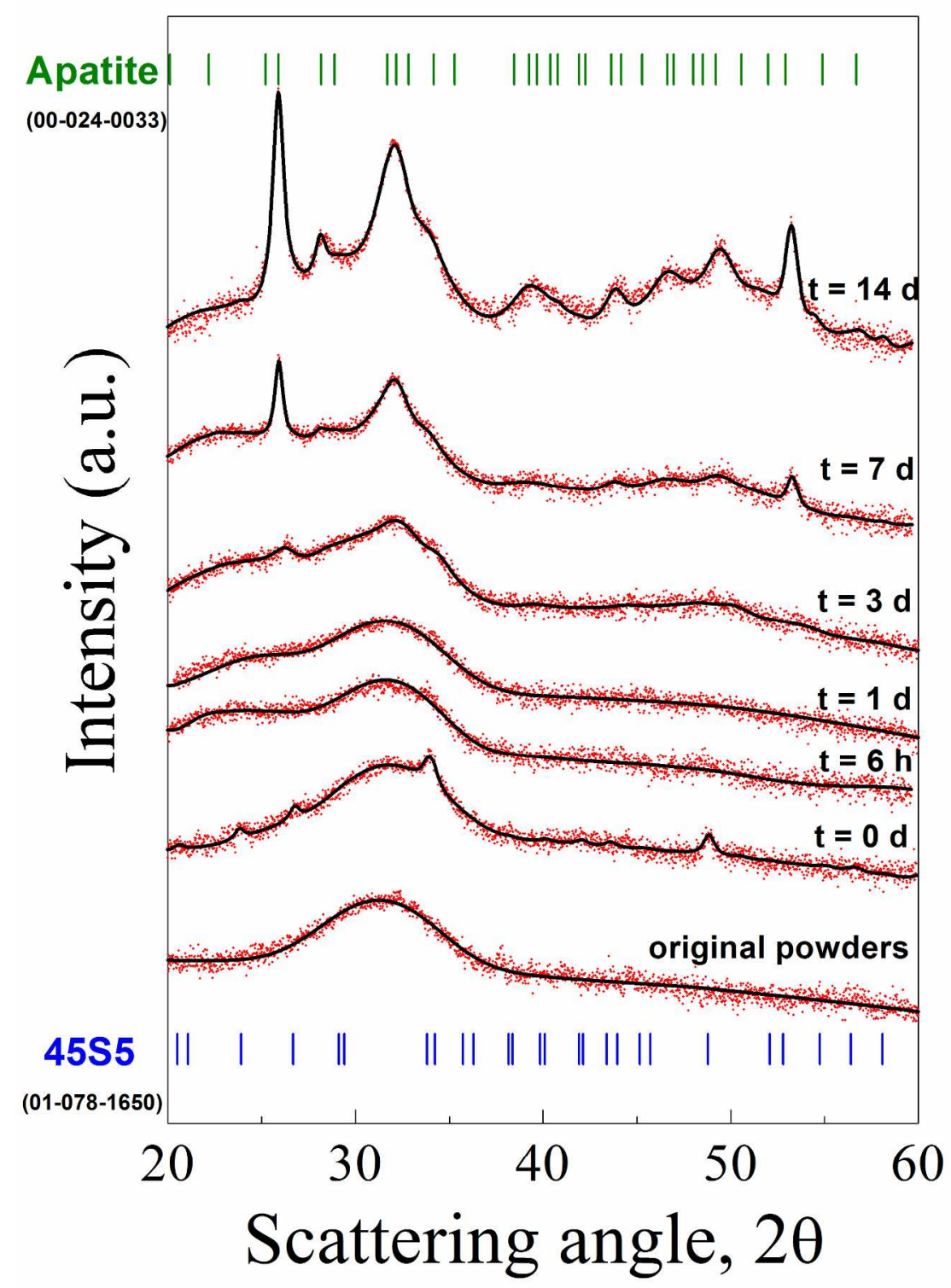

Figure 1. XRD patterns and related Rietveld refinements of 45S5_S1 samples as a function of the immersion time in the SBF solution. Data relative to the original bioglass powders are also shown for the sake of comparison. Label $45 \mathrm{~S} 5$ refers to the Ca1.5Na2.64Si9O3 phase.

$201 \times 287 \mathrm{~mm}(300 \times 300 \mathrm{DPI})$ 


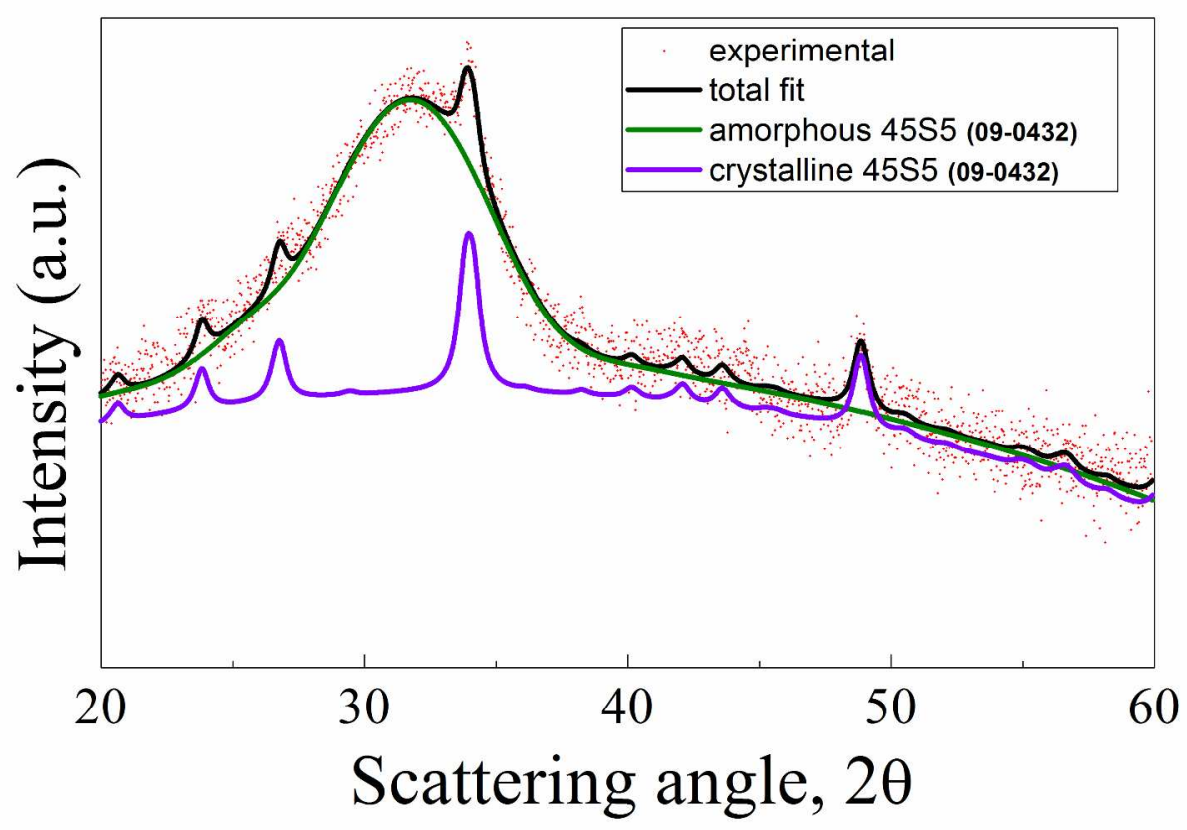

Figure 2. Deconvolution of the XRD pattern relative to the SPSed 45S5_S1 product before being immersed in the SBF solution.

$288 \times 201 \mathrm{~mm}(300 \times 300 \mathrm{DPI})$ 


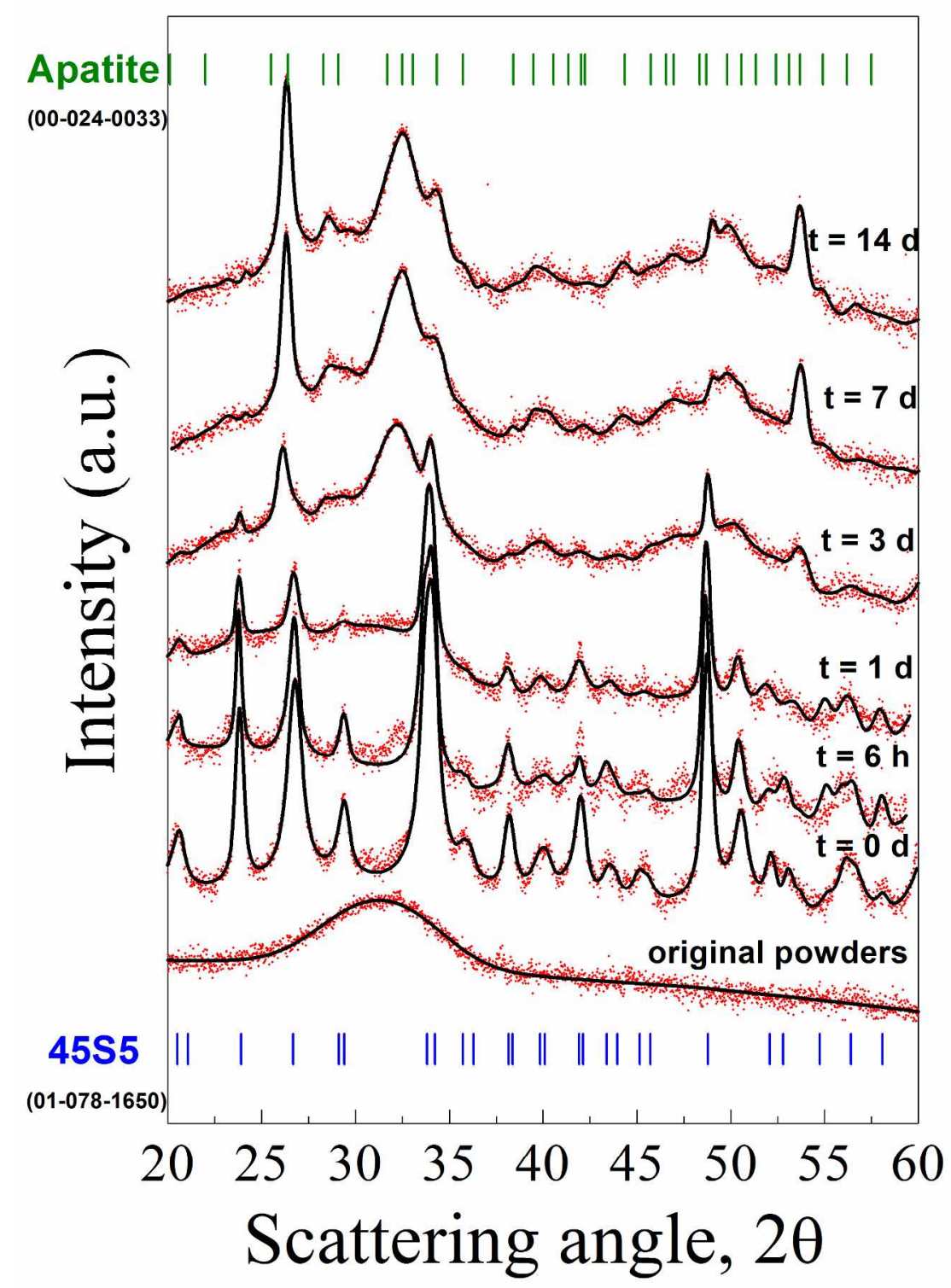

Figure 3. XRD patterns and related Rietveld refinements of 45S5_S2 samples as a function of the immersion time in the SBF solution. Data relative to the original bioglass powders are also shown for the sake of comparison. Label $45 \mathrm{~S} 5$ refers to the Ca1.5Na2.64Si9O3 phase.

$201 \times 287 \mathrm{~mm}(300 \times 300 \mathrm{DPI})$ 


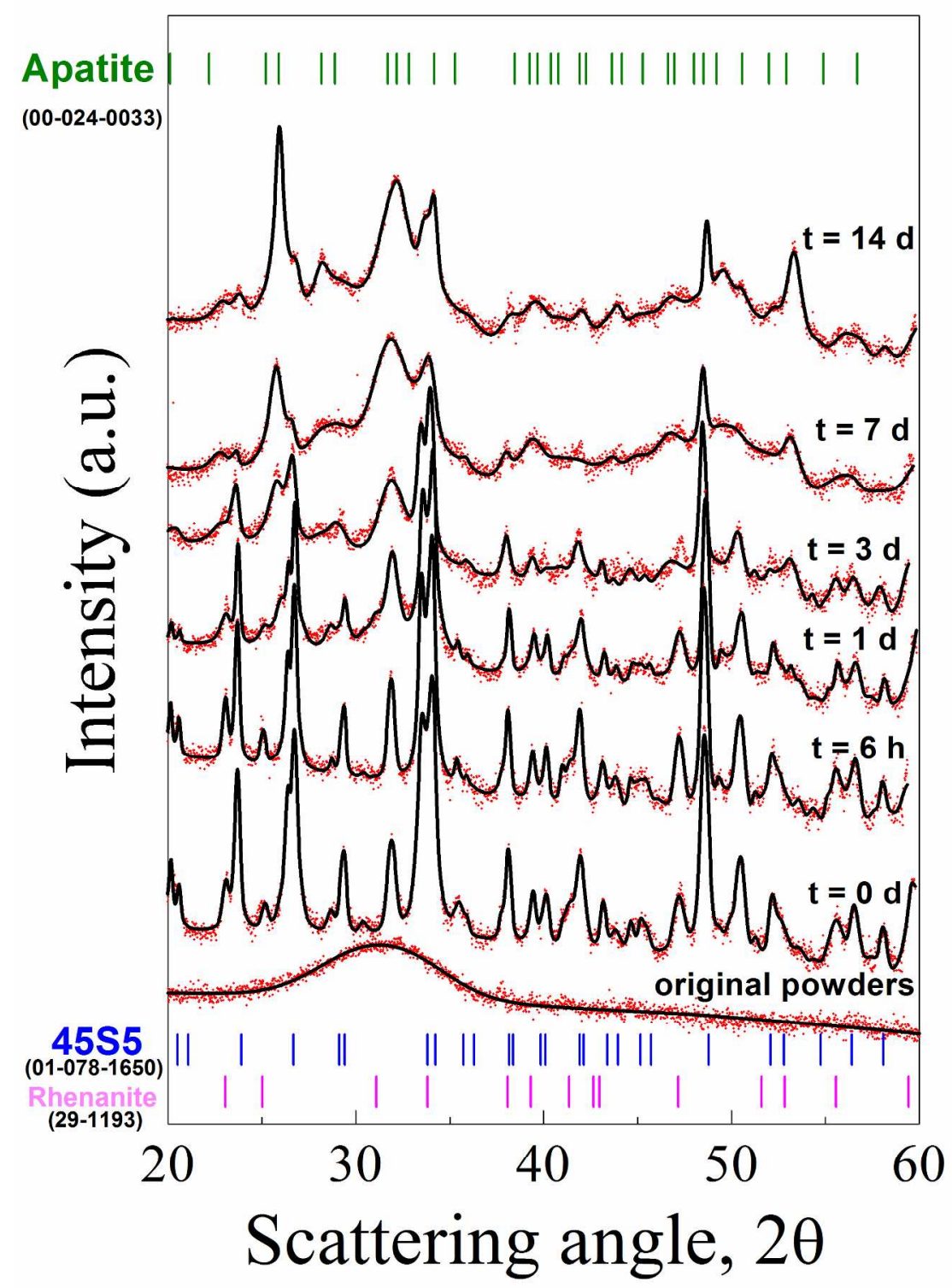

Figure 4. XRD patterns and related Rietveld refinements of 45S5_S3 samples as a function of the immersion time in the SBF solution. Data relative to the original bioglass powders are also shown for the sake of comparison. Label $45 \mathrm{~S} 5$ refers to the Ca1.5Na2.64Si9O3 phase.

$201 \times 287 \mathrm{~mm}(300 \times 300$ DPI) 


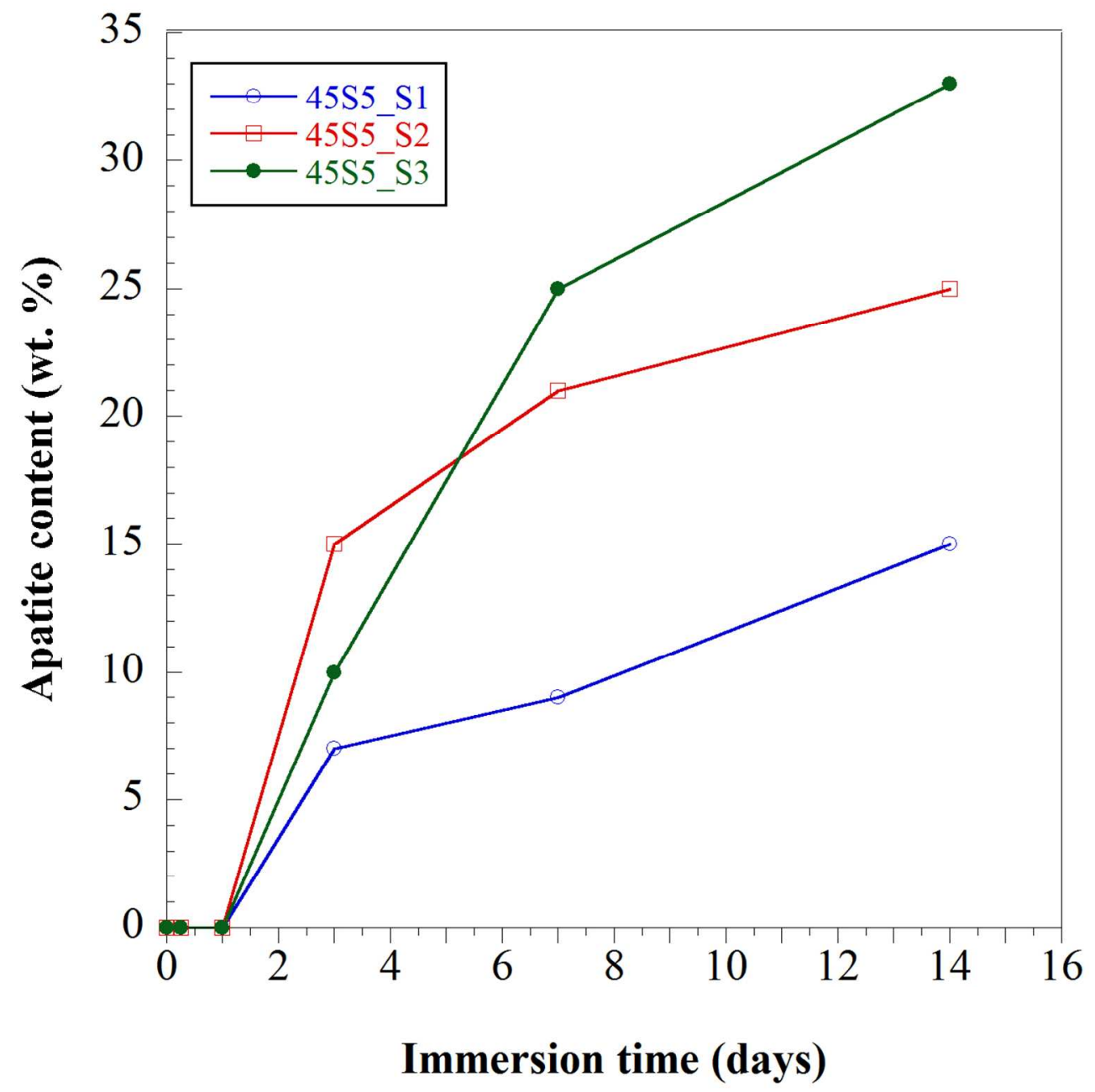

Figure 5. Temporal changes of apatite content on the surface of the three class of 45S5-bioglass samples during in-vitro test, as revealed by the Rietveld analysis.

$116 \times 117 \mathrm{~mm}(288 \times 288 \mathrm{DPI})$ 


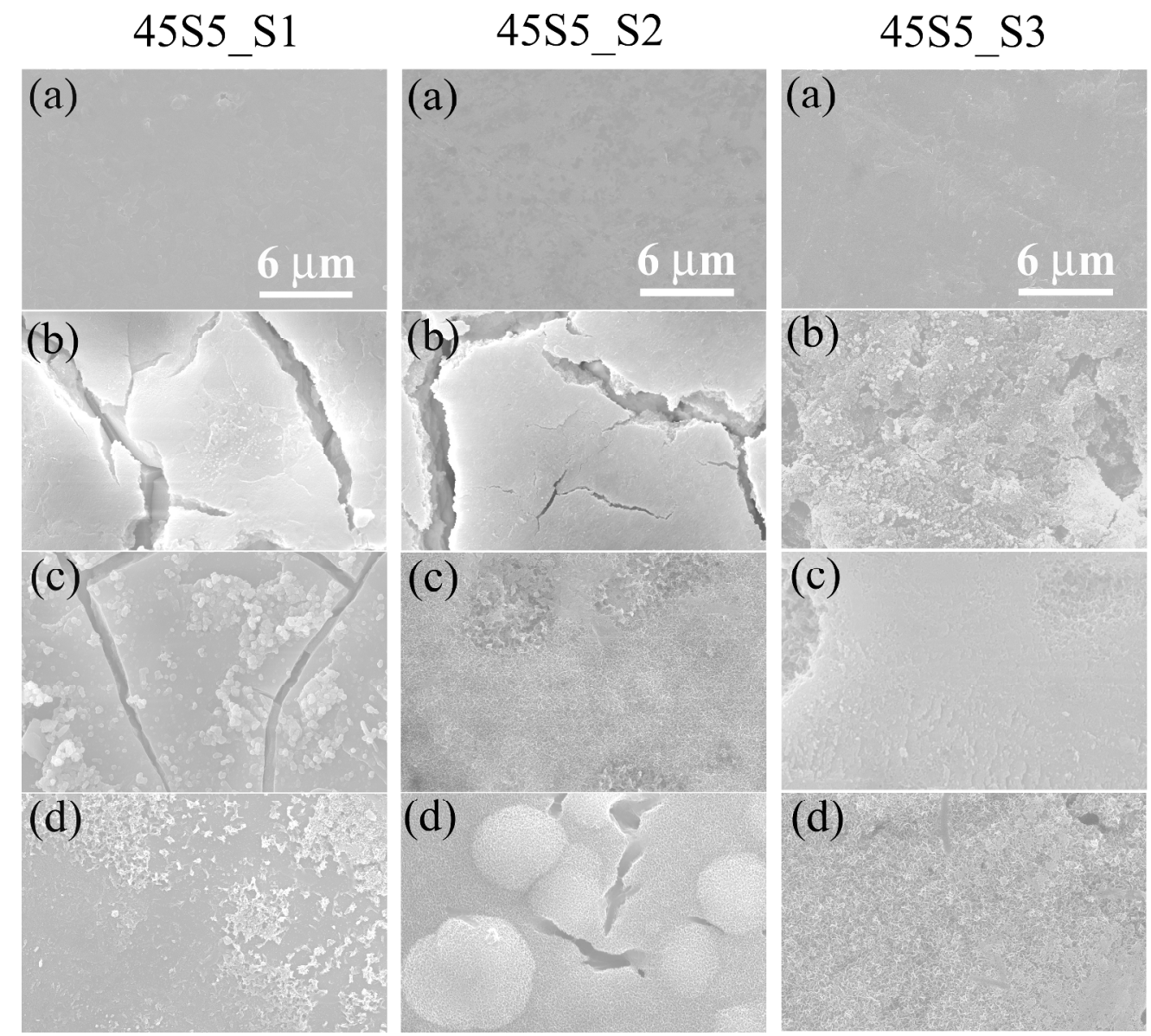

Figure 6. SEM micrographs (5000X) of the three groups of 4555 specimens at different immersion times in the SBF solution: (a) $0 \mathrm{~h}$, (b) $6 \mathrm{~h}$, (c) $1 \mathrm{~d}$, and (d) $3 \mathrm{~d}$. 

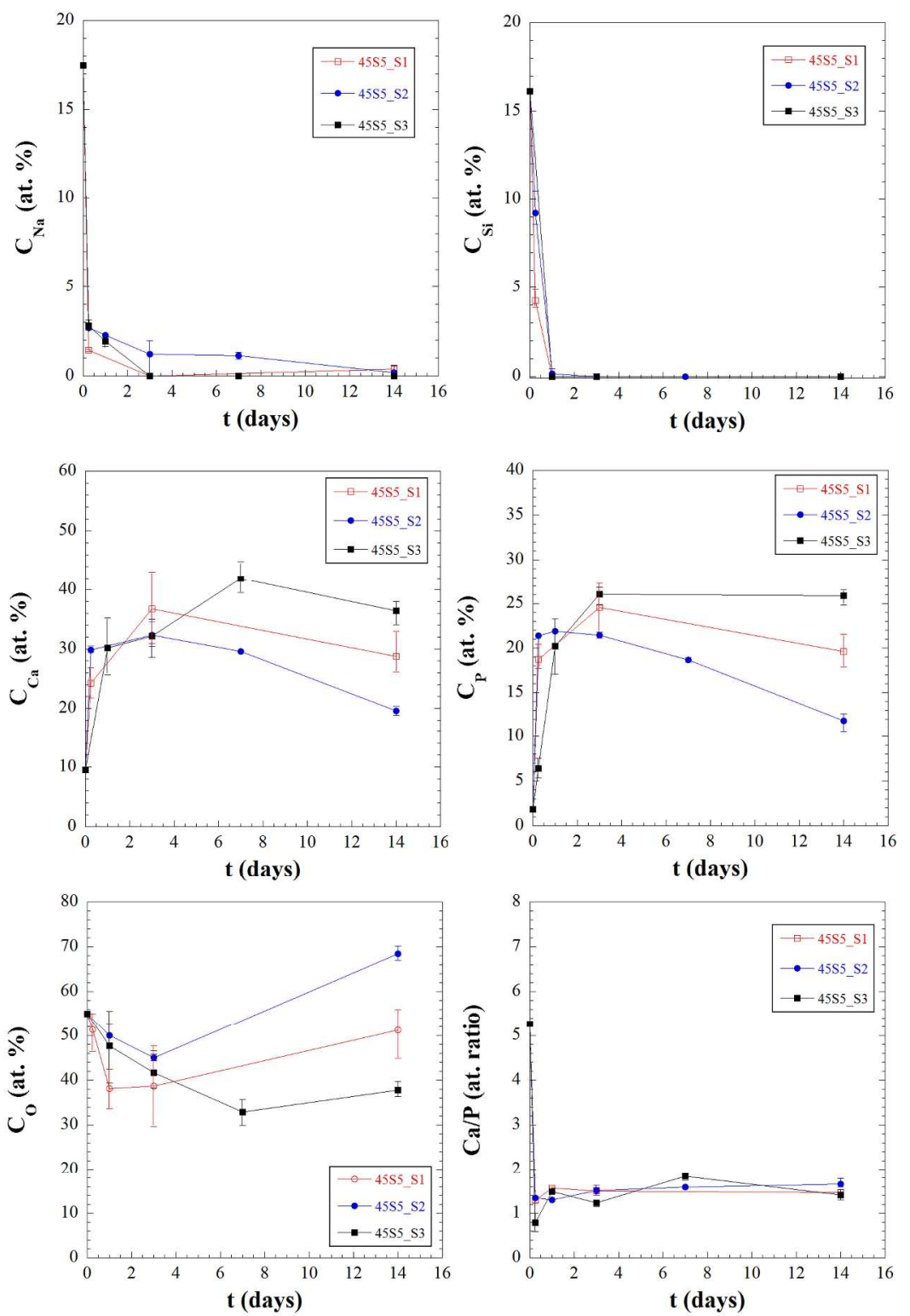

Figure 7. Compositional changes, as revealed by EDX analysis, taking place on the surface of the three groups of $45 \mathrm{~S} 5$ specimens during their immersion in the SBF solution. 

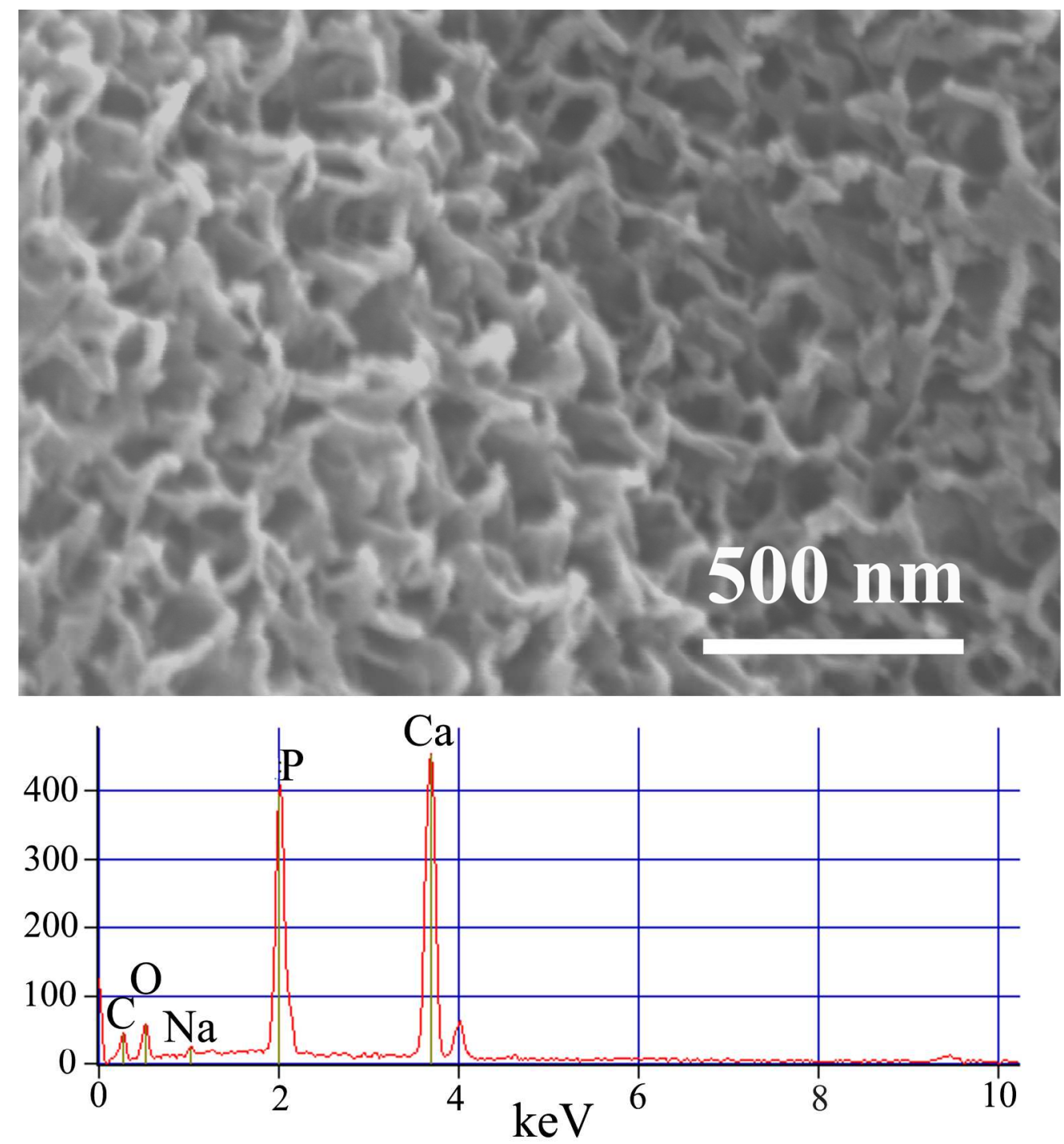

Figure 8. Detailed micrograph, and related EDX spectra, of the surface of 45S5_S2 sample after immersion for 3 days in the SBF solution. The EDX analysis provided the following results: Ca: 34 at. \%, P: 21 at.\%, O: 44 at. \%, and $\mathrm{Na}: 1$ at.\%. The contribution of the $\mathrm{C}$ signal was not considered, due to the presence of graphite used to guarantee the electric contact in samples examined by SEM. 
Figure 9. Raman spectrum of the 45S5_S2 sample immersed for 3 days in SBF. The Raman data of pure apatite is also shown for the sake of comparison.

$287 \times 201 \mathrm{~mm}(300 \times 300$ DPI) 


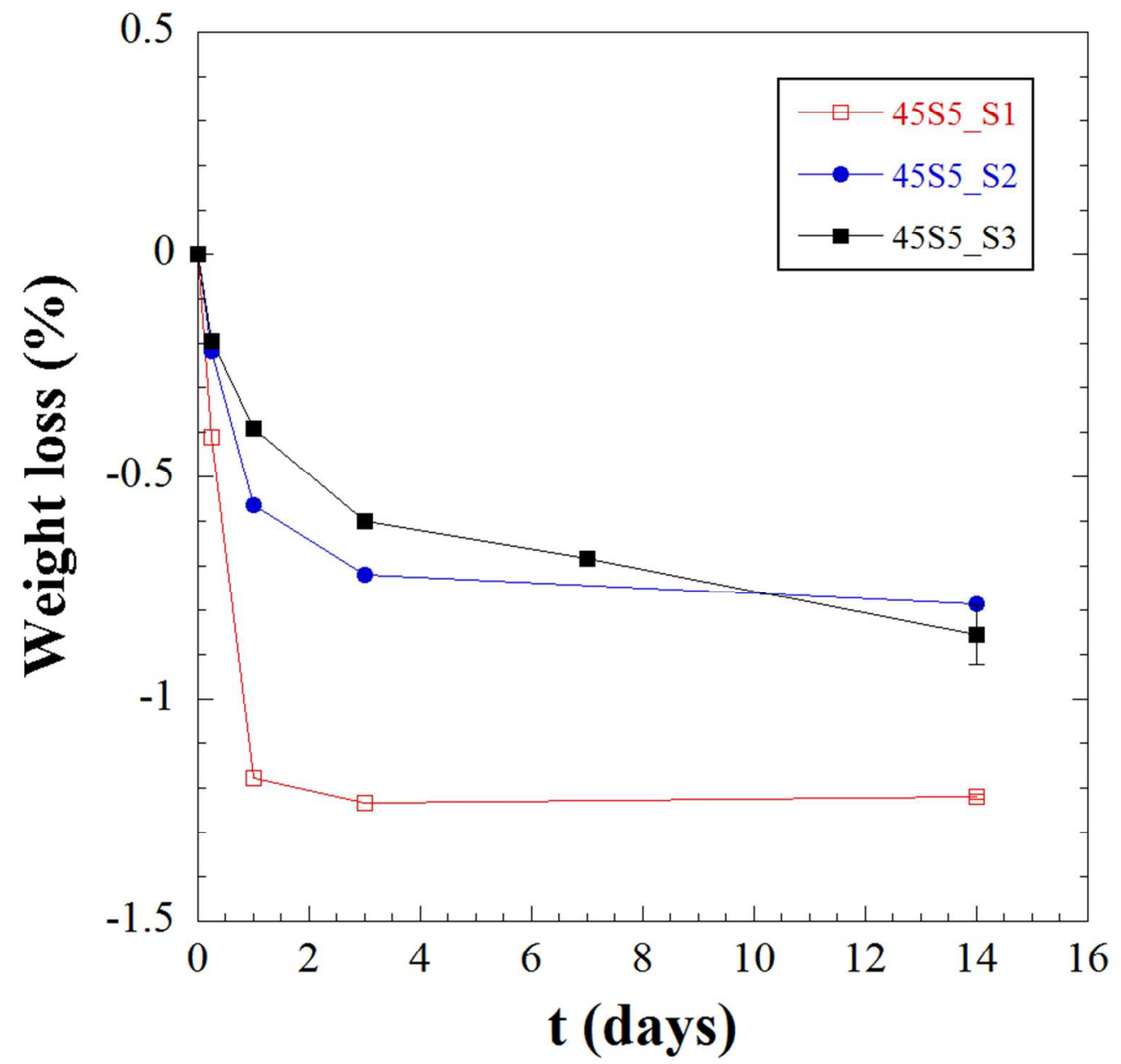

Figure 10. Weight changes of the three groups of 45SS specimens as a function of immersion times in the SBF solution.

$79 \times 76 \mathrm{~mm}(288 \times 288$ DPI $)$

Journal of the American Ceramic Society 
Figure 11. Temporal evolution in $\mathrm{pH}$ of the SBF solutions where the three groups of $45 \mathrm{~S} 5$ specimens were immersed.

$88 \times 85 \mathrm{~mm}(288 \times 288$ DPI $)$ 

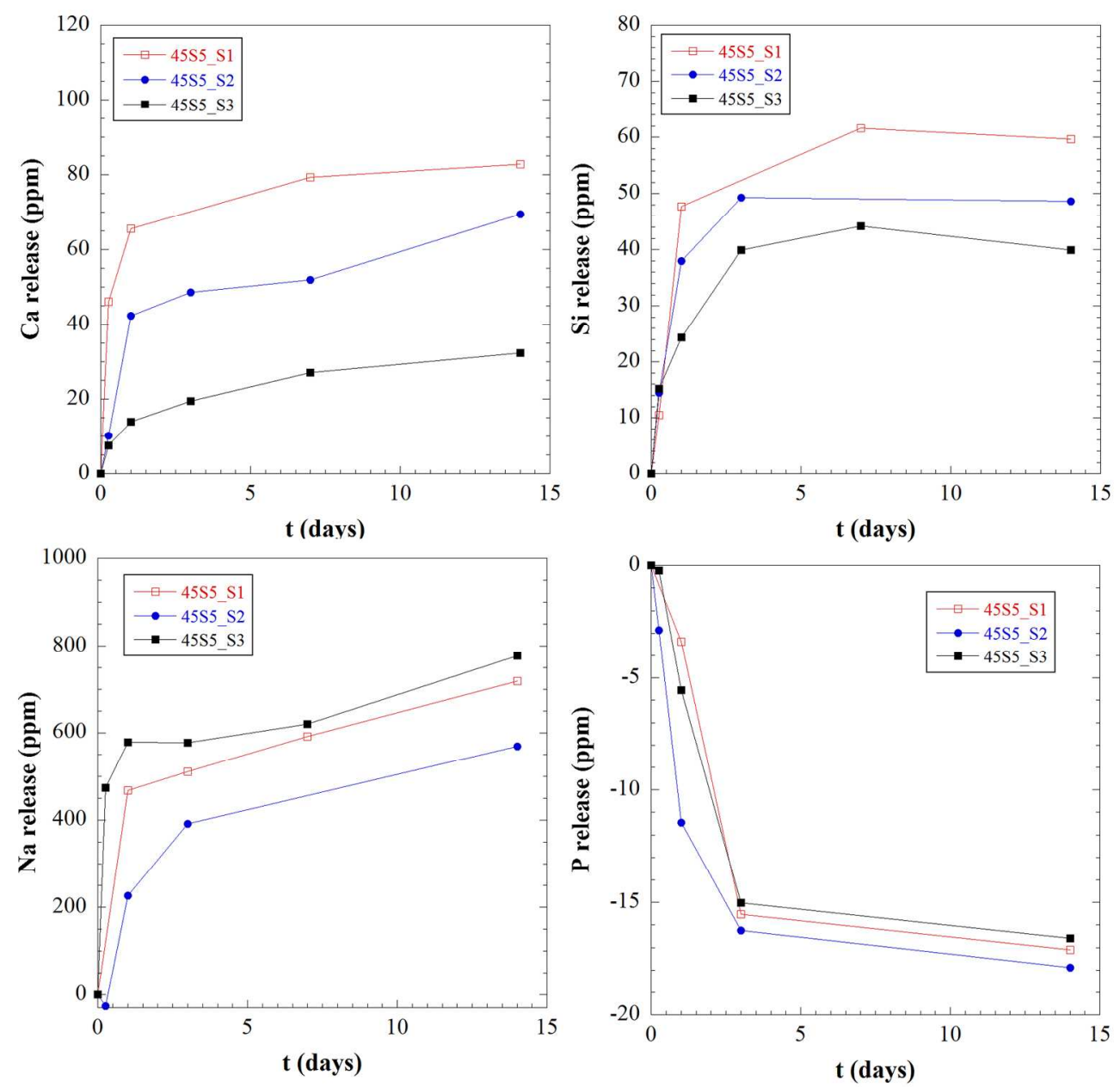

Figure 12. Compositional changes of the SBF solutions where the three series of $45 \mathrm{~S} 5$ samples were soaked up to 14 days. 